\title{
Impact evaluation and interventions to address climate change: a scoping study
}

Prowse, Martin; Snielsveit, Birte

Published in:

Journal of Development Effectiveness

DOI:

$10.1080 / 19439341003786729$

Publication date:

2010

Document version

Early version, also known as pre-print

Citation for published version (APA):

Prowse, M., \& Snielsveit, B. (2010). Impact evaluation and interventions to address climate change: a scoping study. Journal of Development Effectiveness, 2(2), 228-262. https://doi.org/10.1080/19439341003786729 
This article was downloaded by: [Universiteit Antwerpen Bibliotheek]

On: 2 July 2010

Access details: Access Details: [subscription number 919116054]

Publisher Routledge

Informa Ltd Registered in England and Wales Registered Number: 1072954 Registered office: Mortimer House, 3741 Mortimer Street, London W1T 3JH, UK

\section{Journal of}

\section{Development Effectiveness}

\section{Journal of Development Effectiveness}

Publication details, including instructions for authors and subscription information: http://www.informaworld.com/smpp/title content=t906200215

\section{Impact evaluation and interventions to address climate change: a scoping study \\ Martin Prowse ${ }^{\mathrm{a}}$; Birte Snilstveit ${ }^{\mathrm{b}}$ \\ ${ }^{\mathrm{a}}$ Institute of Development Policy and Management (IOB), University of Antwerp, Belgium ${ }^{\mathrm{b}}$ International Initiative for Impact Evaluation, New Delhi, India}

Online publication date: 28 June 2010

To cite this Article Prowse, Martin and Snilstveit, Birte(2010) 'Impact evaluation and interventions to address climate change: a scoping study', Journal of Development Effectiveness, 2: 2, $228-262$

To link to this Article: DOI: $10.1080 / 19439341003786729$

URL: http://dx.doi.org/10.1080/19439341003786729

\section{PLEASE SCROLL DOWN FOR ARTICLE}

\footnotetext{
Full terms and conditions of use: http://www.informaworld.com/terms-and-conditions-of-access.pdf

This article may be used for research, teaching and private study purposes. Any substantial or systematic reproduction, re-distribution, re-selling, loan or sub-licensing, systematic supply or distribution in any form to anyone is expressly forbidden.

The publisher does not give any warranty express or implied or make any representation that the contents will be complete or accurate or up to date. The accuracy of any instructions, formulae and drug doses should be independently verified with primary sources. The publisher shall not be liable for any loss, actions, claims, proceedings, demand or costs or damages whatsoever or howsoever caused arising directly or indirectly in connection with or arising out of the use of this material.
} 


\title{
Impact evaluation and interventions to address climate change: a scoping study
}

\author{
Martin Prowse $^{\mathrm{a}}$ and Birte Snilstveit ${ }^{\mathrm{b} *}$ \\ ${ }^{a}$ Institute of Development Policy and Management (IOB), University of Antwerp, Belgium; \\ ${ }^{b}$ International Initiative for Impact Evaluation, New Delhi, India
}

\begin{abstract}
Substantial and increasing amounts of funding are available for countries to undertake climate change interventions. This article argues that to ensure effective allocation of these resources, the selection and design of climate change mitigation and adaptation interventions should be based on evidence of what works, what doesn't work, under what circumstances and at what cost. Currently the evidence base on the impact of climate change interventions is minimal and there is a need for wider application of rigorous impact evaluation (IE) in the field. Climate change interventions have much to learn from experiences in related fields, notably international development and conservation. The paper highlights some of the challenges faced when conducting IEs of climate change interventions and discusses how these can be tackled. Moreover, it discusses some of the key areas of mitigation and adaptation interventions and suggests how IEs could be implemented, using IEs from other policy fields as examples. It argues that despite the limited experience so far there are ample opportunities to conduct IE of climate change interventions. If calls for increasing financing of climate change mitigation and adaptation by hundreds of billions of dollars a year are to remain credible and gain support, evidence of the effectiveness of current spending is essential.
\end{abstract}

Keywords: impact evaluation; climate change; interventions

\section{Introduction and background to study}

Climate change is at the top of the international policy agenda. While differences in interests and negotiating positions make ongoing negotiations challenging, there is broad agreement on the need to tackle the causes and consequences of global climatic change. But although the evidence base on the science of climate change is overwhelming, there is less of a consensus around the effectiveness of policies and interventions designed to bring about behaviour change for mitigation and adaptation. So far very few rigorous impact evaluations (IEs) of climate change interventions have been undertaken: the evidence base to guide policy-makers needs strengthening.

This paper argues that to support the effective allocation of substantial climate funds, the selection and design of climate change interventions (both mitigation and adaptation) should be based on evidence of what works and what does not, under what circumstances and at what cost. This paper is intended to be of relevance to climate change professionals on the one hand, and to impact evaluators on the other. However, as the applicability of IE techniques to climate change interventions has not been widely considered, the paper does

*Corresponding author. Email: bsnilstveit@3ieimpact.org 
not purport to be comprehensive or exhaustive. Instead, it sketches out the terrain on which future studies might build.

Section 2 of the paper provides an introduction to climate change, policy responses and sources of funding. We briefly summarise the science of climate change and its physical impacts, provide some background on what is meant by mitigation and adaptation, and provide an overview of the main financial resources available through the United Nations Framework Convention on Climate Change (UNFCCC) and other multilateral sources.

The remaining sections of the paper discuss IEs in relation to climate change interventions. Section 3 provides a brief introduction to IE, a summary of how it has been applied to climate change, related environmental interventions in developing countries to date, and a brief discussion of the limits and opportunities in applying rigorous IE to climate change interventions. Sections 4 and 5 focus on some of the key areas relevant for mitigation and adaptation interventions, respectively, and suggest ways in which IEs could be implemented, using evaluations in other policy fields as examples. As stated above, there is ample scientific evidence regarding climate change and the science behind proposed interventions for mitigation and adaptation. But underlying the success of these interventions is behaviour change, and Section 6 concludes that it is this behaviour change that has been inadequately evaluated.

\section{Overview of climate change, policy responses and funding streams}

Climate change is shorthand for anthropogenic global warming, caused by higher concentrations of greenhouse gases (GHGs) in the atmosphere, especially carbon dioxide $\left(\mathrm{CO}_{2}\right)$ from the combustion of fossil fuels. These gases insulate and warm the earth by preventing infrared radiation from escaping back into space. The evidence that human activity is causing the earth's temperature to increase is overwhelming (see Intergovernmental Panel on Climate Change [IPCC] 2007a, 2007b, Liverman 2007, 2008, Anderson and Bows 2008). Higher temperatures are having a profound effect on environmental systems, increasing sea levels, thawing glaciers and permafrost, and changing the spatial distribution of plant and animal species.

In addition to the impact on environmental systems, climate change has become one of the most pressing international development issues. Anthropogenic global warming threatens, inter alia, to alter the spatial distribution of infectious and respiratory diseases, increase weather-related mortality, increase the salinity and temperature of oceans (altering fish stocks), modify the supply, demand and quality of freshwater, radically alter crop yields and the area of arable land, and increase the frequency and severity of natural hazards (Fischer et al. 2002, Kahn 2005, Warren et al. 2006, Dasgupta et al. 2007, IPCC 2007b, Food and Agriculture Organisation [FAO] 2007, 2008, Cline 2007, Dell et al. 2009, World Bank 2009b). It is hard to disagree with the Human Development Report 2007/08 assertion that climate change is 'the defining human development issue of our generation' (United Nations Development Programme [UNDP] 2007, p. 1). A statement supported by the attendance of 119 heads of state and government (representing 89 per cent of global Gross Domestic Product) in Copenhagen for the 15th Conference of Parties in December 2009.

Whether we look at the projected impacts of climate change on crop yields, areas of arable land, natural hazards, or sea-level rise, it is clear that the consequences of climate change will be distributed unequally, affecting the poorest countries disproportionately, as they are more likely to rely on natural resources and economic sectors that are vulnerable to climate change, such as agriculture, fisheries and forestry (see Reid and Swiderska 2008). Moreover, climate change is likely to have the greatest negative impact on the poorest sections of populations. We 
know that the poorest citizens are most likely to be: found in remote and unconnected rural areas; derive most of their income, directly or indirectly, from agriculture or natural resources; live in insecure environments and have few assets or entitlements to cope with shocks and stresses; have limited political voice and representation; and have little access to decent work opportunities (Chronic Poverty Research Centre [CPRC] 2008). It is likely that the physical effects of climate change will make these poverty traps more severe and 'create a vicious cycle of poverty and vulnerability' (Ibarrarán et al. 2009, p. 563).

In sum, the risks from climate change are greatest for the poorest countries and for the poorest sections of societies, and there is a profound sense of injustice if the poorest are forced to suffer most from the physical impacts of climate change (see Thomas and Twyman 2005, Paavola and Adger 2006). We thus have a moral as well as an economic case for global interventions to finance climate change interventions to reduce emissions and limit the adverse effects of global environmental change.

\subsection{Climate change mitigation}

Climate change interventions are divided into two broad categories: mitigation and adaptation. Mitigation interventions are designed to tackle the causes of climate change, while adaptation refers to interventions designed to assist people and countries in tackling the effects of climate change. ${ }^{1}$ We give a brief summary of each, with particular reference to developing countries. ${ }^{2}$

Climate change mitigation refers to policies that reduce GHG emissions and preserve/ expand carbon sinks. ${ }^{3}$ Because of the large number of human activities that contribute to emissions, interventions to mitigate climate change are implemented across a range of sectors and industries, such as energy, transport, industrial production, waste management, and agriculture and forestry (UNFCCC 2008).

Barker et al. (2007) estimate that in 2004 the most important sources of GHG emissions were energy supply (26\%), industry (19\%) and forestry (17\%). In addition, current GHG emissions from agriculture are estimated at around 14 per cent, with high emission increases expected for the future (UNFCCC 2009). The sources of emissions vary widely between developed (Annex I) and developing (non-Annex I) countries. For example, a breakdown of $\mathrm{CO}_{2}$ emissions by sector in 2000 shows us that, for OECD countries, emissions stem mainly from electricity and heat, manufacturing and construction, transportation and other fuel combustion (World Resources Institute 2009). This is also the case for China and India. However, for much of the rest of Asia, sub-Saharan Africa and South and Central America, the majority of emissions come from land use change and forestry. For instance, a breakdown of emission sources in 2000 for sub-Saharan Africa shows that 75 per cent come from this source (World Resources Institute 2009).

As compared to the previous century when developed countries emitted the vast bulk of (non-land-use) emissions, the distribution of emissions has changed radically in the past two decades. Due to the global shift in manufacturing and rapid industrialisation in parts of Asia, developing countries now have the majority of energy-intensive industry, and account for a greater proportion of final energy use by industry than the developed world, with this proportion set to increase (Barker et al. 2007). Moreover, transport energy use in the developing world is projected to increase by 3-5 per cent per year in the coming decades, bringing its share of total energy use at par with the developed world by around 2030 (Barker et al. 2007).

But despite the shift in (non-land-use) emissions from developed to developing countries, and the position of China as the world's largest annual emitter of $\mathrm{CO}_{2}$, developed countries will continue to owe a greater 'ecological debt' than developing countries for some 
time to come. There are two main reasons: population size, and the amount of time $\mathrm{CO}_{2}$ stays in the atmosphere. On a per-capita basis, (non-land-use) emissions from Canada, the United States and Russia are projected to be at least double to that of China's emissions in 2030 (at a similar level to European Union [EU] levels) (Financial Times 2009). Since $\mathrm{CO}_{2}$ remains in the atmosphere for around 100 years (IPCC 2007a) we can better compare (non-land-use) per-capita cumulative emissions, instead of annual emissions, according to which by 2030 Chinese emissions will still be less than one-fifth of emissions from the United States, Canada and Russia and one-third of EU emissions (Financial Times 2009).

A post-Kyoto climate regime needs to reach a fair and just balance between emission reductions in developed and developing countries to avert dangerous climate change. The levels of $\mathrm{CO}_{2}$ in the atmosphere in 2008 were 385.2 ppm, increasing by 2 ppm from 2007 (World Meteorological Organisation 2009). The IPCC's best estimates are that if levels reach $450 \mathrm{ppm} \mathrm{CO} \mathrm{CO}_{2} \mathrm{e},{ }^{4}$ there is a 50 per cent chance of a $2^{\circ} \mathrm{C}$ temperature increase. If we reach 550 ppm and $650 \mathrm{ppm}$ there is a 50 per cent chance of $3^{\circ} \mathrm{C}$ and $4{ }^{\circ} \mathrm{C}$ temperature increases respectively (see also Anderson and Bows 2008). And as $\mathrm{CO}_{2}$ stays in the atmosphere for at least 100 years, even if emissions peak in the next 25-50 years, stocks in the atmosphere will only stabilise in 100-300 years (IPCC 2001). This means that temperature stabilisation will only take place over a few centuries, and that, due to thermal expansion and ice melt, sea levels will continue to rise for much longer. In other words, reducing GHG emissions now will influence the climate for hundreds, if not thousands, of years (IPCC 2001).

Concomitant with the greatest sources of GHG emissions, a large proportion of mitigation activities have so far been focused in the energy and transport sectors, including energy efficiency measures, fuel switching, the use of renewable energy and biofuels (World Bank 2009a). ${ }^{5}$ In addition to reducing carbon emissions, climate change mitigation also takes the form of preserving and expanding carbon sinks such as forests. Global forest cover equates to around 30 per cent of global land area, but is shrinking rapidly due to the pressures of agriculture, infrastructure and urbanisation. Forests play a particularly important role in climate change. On the one hand, forests act as a store that contains twice the amount of carbon present in the atmosphere. On the other hand, each year forests actively remove up to one-third of all $\mathrm{CO}_{2}$ emissions from fossil fuel combustion and land-use change (McMullen and Jabbour 2009). This vital role in maintaining the globe's carbon cycle can be supported in a number of ways. For example, through increasing a forest's carbon density and through utilising sustainably-harvested forest products in place of items with a large carbon footprint (see McMullen and Jabbour 2009). Most importantly, however, forests' vital role can be supported through reducing deforestation. Estimates suggest that around one-fifth of global GHG emissions stem from tropical deforestation, concentrated particularly in Indonesia and Brazil (see Porrúra et al. 2007).

As is the case with adaptation, many mitigation interventions share similarities with development activities. For example, the introduction of new technologies, sustainable agricultural practices, and the production of new products and services, such as biofuels and environmental services - all of which can provide new sources of income and wellbeing in addition to reducing GHGs.

\subsection{Climate change adaptation}

Despite receiving less attention than mitigation in recent years, adaptation is now also at the forefront of climate policy, as the impacts of climate change are already being observed and its worse impacts are inevitable (see McGray et al. 2007, Parry et al. 2007, Rosenzweig et al. 2007). As Smit and Wandel (2006) note, while there are countless definitions of adaptation in 
the conceptual literature, most definitions refer to a common theme; namely, the adjustment of individual groups, systems and institutions to a changing climate, including an increase in external shocks, in order to reduce vulnerability and thus improve the capacity to cope with and reduce the negative impacts of climate change. For instance, the IPCC (2001, p. 982) defines adaptation as: 'adjustment in natural or human systems in response to actual or expected climatic stimuli or their effects, which moderates harm or exploits beneficial opportunities'.

There is an extensive literature conceptualising different types of adaptation. Distinctions are made between ex-ante (anticipatory) or ex-post (reactive) adaptation, and planned and autonomous adaptation (Mitchell and Tanner 2007). ${ }^{6}$ As the purpose of this paper is to discuss practical aspects of interventions, we do not detail the conceptual debate here (for the wider literature, see, for example, Adger et al. 2003, 2005, 2009, Paavola and Adger 2006, Pielke et al. 2007).

Despite developing countries having the greatest adaptation need (as they face the greatest risks from climatic change), a relatively small number of adaptation activities have been implemented to date (due in part to low levels of funding and a lack of knowledge of climate data and data processing skills). Those that have been undertaken have mainly focused on preparing for adaptation through capacity-building and assessments of vulnerability and options for adaptation (Burton et al. 2006, Global Environment Facility [GEF] 2007).

Hence, there are signs of a slow move towards implementation of adaptation activities on the ground, and a number of GEF-funded projects are now underway, focusing on enhancing food security, access to water, public health and coastal infrastructure (GEF 2007). ${ }^{7}$ Other examples include crop and livelihood diversification, seasonal climate forecasting, community-based disaster risk reduction, famine early warning systems, insurance, natural resource management, water storage and supplementary irrigation (Adger et al. 2007, Hedger et al. 2008, Huq and Reid 2004, World Bank 2009a).

A recent review study identified 135 adaptation activities (McGray et al. 2007). The results suggest the majority of interventions were implemented in rural areas, at the village or community level, with few national-level interventions being identified. In terms of sectoral distribution, agriculture and disaster risk management dominate, followed by water resources management and coastal resources, with very few interventions undertaken in the human health and energy sectors.

As these finding suggest, the distinction between 'adaptation' and 'development' is rather blurred. In his Foreign Policy Centre 2008 annual lecture, Douglas Alexander, the UK's Secretary of State for International Development, went so far as to argue that 'adaptation simply means development under the conditions of a changing climate' (Alexander 2008). The overlap between adaptation and development activities is also noted by McGray et al. who, in identifying 12 different adaptation strategies, suggest that 'if there are uniquely "adaptive" elements to these efforts, they are those involved in defining problems, selecting strategies, and setting priorities, not in implementing solutions' (2007, p. 15) (see also Hedger et al. 2008).

It is therefore unsurprising that there are increasing calls for including adaptation in mainstream development efforts (OECD 2006, 2009a, 2009b). For example, many strategies from the 'development toolbox' are now being promoted as adaptation activities, including microfinance services (Hammhill et al. 2008), social protection (in the form of weatherindexed crop insurance, asset restocking and cash transfers) (Commission on Climate Change and Development 2009, Oswald 2009), agricultural extension services (Commission on Climate Change and Development 2009), and disaster risk reduction (see O'Brien et al. 2008, Thomalla et al. 2006, International Strategy for Disaster Reduction [ISDR] 2009, Yamin et al. 2005). 


\section{Impact evaluation and climate change interventions}

\subsection{What is impact evaluation?}

Recent years has seen a vibrant debate on the increasing use of IE in international development (see White 2009a, 2009c). Broadly speaking, IE is structured to answer the question: how would participants' welfare have altered if the intervention had not taken place? This counterfactual analysis involves 'a comparison between what actually happened and what would have happened in the absence of the intervention' (White 2006, p. 3). Since it is not possible to collect data on what would have happened if the intervention was not implemented, IE uses different methods to create a robust comparison group who is not directly exposed to the intervention, and whose outcomes would have been similar to participants if the intervention had not taken place (White 2006). Such counterfactual analysis enables researchers to attribute the changes in outcome to particular interventions. Methods for establishing a valid counterfactual include experimental (randomisation), and quasi-experimental approaches; there may also be opportunities to exploit 'natural experiments'. In addition to overcoming attribution and selection bias issues, IE can form the basis for cost-benefit analysis to assess the efficiency of different interventions (see White 2009c).

This paper follows the International Initiative for Impact Evaluation (3ie) in defining rigorous IEs as:

analyses that measure the net change in outcomes for a particular group of people that can be attributed to a specific program using the best methodology available, feasible and appropriate to the evaluation question that is being investigated and to the specific context. (3ie International Initiative for Impact Evaluation 2008, p. 2)

IE assesses the impact of an intervention using counterfactual analysis. The estimated impact of the intervention is calculated as the difference in mean outcomes between a 'treatment group' (those receiving the intervention) and a 'control group' (those who do not). The single difference estimator compares mean outcomes at end-line and is valid where treatment and control groups have the same outcome values at baseline. The difference-indifference (or double difference) estimator uses baseline and end-line data to calculate the change in outcomes over time across the two groups. There are various approaches to determining an appropriate comparison group for counterfactual analysis:

- Randomisation. The experimental approach to IE involves the random selection of participants into the intervention and control groups. When this method is well implemented over a sufficiently large sample, the only difference between the two groups is that the control group does not receive the intervention. The experimental approach is held up by some as the 'gold standard' of evaluation, but is not applicable to all interventions. See Skoufias (2001) for an example.

- Pipeline. This approach uses people, households, communities or businesses already chosen to participate in a project at a later stage as the comparison group. The assumption is that as they have been selected to receive the intervention in the future they are similar to the treatment group, and therefore comparable in terms of outcome variables of interest. See Edmonds (2002) for an example.

- Matching. This approach involves matching programme participants to non-participants based on a number of observed criteria. One such approach is that of propensity score matching, which uses a statistical model to calculate propensity of participation on the basis of the set of observable characteristics. Participants and non-participants are then matched on the basis of similar propensity scores. A second approach is regression 
discontinuity design, which exploits a decision rule as to who does and does not get the intervention to compare outcomes for those just either side of this cut-off. See Kassie et al. (2009) for an example of a study using matching.

- Other techniques. The other techniques of IE include interrupted time-series and regression-based designs.

For a discussion of IE approaches, see White (2006). Additionally, 3ie has recently launched an online database with a range of IEs conducted in low-income and middle-income countries.

As with all social research methods, experimental and quasi-experimental approaches have potential limitations. For example, the merging of control and treatment groups (such as when a control unit forces itself into the treatment group), spillover effects (when the direct or indirect effects of the intervention leaks over from the treatment group into the control), and a lack of compliance by an implementing agency that compromises the study (for a discussion of some of the pitfalls, see Ravallion 2001, 2005, Chen et al. 2006; see also Prowse and Camfield 2009). Moreover, Bamberger and White (2007) highlight some of the difficulties in applying experimental approaches to development interventions. These include the often heterogeneous and changing contexts of interventions, logistical and practical challenges and difficulties with monitoring service delivery, and estimates that experimental designs are only applicable to 5 per cent of development finance (Bamberger and White 2007). However, a range of quasiexperimental approaches are applicable to a greater number of interventions and these can provide valid impact estimates when applied rigorously.

IE as defined here has thus far been dominated by (quasi-)experimental analysis of the counterfactual, often based on random sample survey data. While formal sample surveys are ideally suited to generate evidence of what works, on their own they are usually less able to improve our understanding of why interventions work or not (see Prowse 2007b), and under which circumstances. Moreover, evidence on the effectiveness of an intervention in achieving its intended outcomes 'does not tell us enough to inform program improvement or policy revision' (Weiss 2007, p. 77). Most interventions within the realm of public policy are of a voluntary, rather than coercive, nature, and will therefore be successful to the extent that people are incentivised to change their behaviour favourably. Therefore we need to know why and how interventions work.

The application of a theory-based approach to IE is one way of improving our understanding of why an intervention is successful or not, and to increase the policy relevance of IEs (see Birkmayer and Weiss 2000, Cook 2000, Rogers 2007, White 2009b). This approach combines rigorous counterfactual impact analysis, as outlined above, with other methods, emphasising analysis of the 'factual' using both quantitative and qualitative methods, to examine the causal chain and shed light on the 'why' and 'how' questions (Leeuw and Vaessen 2009, White 2009b). In the case of climate change interventions, if the reduction of carbon-emitting behaviours is known one can to some extent rely on technical coefficients to calculate carbon reductions from practices like kerosene consumption and air travel. But as behavioural changes and take-up of new technologies are difficult to assess, data from IEs are extremely valuable. Evidence provided by theory-based IEs can improve our understanding of these processes.

White (2009b) outlines six key principles of the theory-based approach:

- Map out the causal chain (programme theory). This involves outlining the theory of how the intervention is expected to lead to the intended impact, enabling the evaluation to test the underlying assumptions along the causal chain. The theory should be 
flexible and ready to adapt to changing circumstances in the field, unforeseen consequences and surprises in the data.

- Understand context. The context of the intervention, including the social, political and economic setting, is critical for understanding the impact of the intervention and designing the evaluation. Doing so would involve reading project documents and the broader literature before designing the evaluation.

- Anticipate heterogeneity. This would assist in identifying sub-groups and adjusting the sample size to account for the levels of disaggregation to be used in the analysis. Examples of sources of impact heterogeneity are socio-economic status and the timing of impact measurement. Understanding context can assist in anticipating possible impact heterogeneity.

- Rigorous evaluation of impact using a credible counterfactual. As many links in the causal chain as possible should be examined using a credible counterfactual (recognising time and resource constraints, the feasibility of constructing a counterfactual, and the significance of these links in the overall chain).

- Rigorous factual analysis. Many of the links in the causal chain call for factual analysis to supplement the counterfactual analysis. Examples that would require such analysis are targeting and output analyses, for instance; did the training lead to improved knowledge and was the knowledge put into practice?

- Use mixed methods. A combination of quantitative and qualitative methods in the same evaluation to provide information on the environmental, political or social context of interventions and provide essential insights into 'why' or 'how' an intervention succeeded or failed. The qualitative data can be generated through a range of activities, including focus groups, in-depth interviews, reading of anthropological and political literature, participatory rural appraisal (PRA) and field visits.

Thus, a theory-based approach to IE (TBIE) includes collecting data at different points along the causal chain to test the underlying assumptions of the programme theory. This provides data on mechanisms between activities and outcomes, enabling evaluators to draw conclusions about the points in the causal chain that led to the measured outcomes (Birkmayer and Weiss 2000). As Birkmayer and Weiss (2000) highlight, TBIE helps to plan evaluations; mapping out the programme theory can act as 'the scaffolding of the study' and assist the researcher in deciding which key assumptions in the programme theory warrants testing and data collection.

As argued by Ferraro (2009), IEs of climate change interventions can benefit from adopting a theory-based approach, not least as evaluations of both mitigation and adaptation interventions include measuring intermediate outcomes, and in such cases a theory-based approach can improve validity. Moreover, as TBIE can provide insights into how and why interventions are effective or not, including evidence on causal mechanisms and contextual factors, this approach can improve the external validity and thus wider policy relevance of evaluations. ${ }^{8}$

\subsection{Applying impact evaluation to climate change interventions}

In this sub-section we examine how approaches to IE have been applied to climate change interventions and environmental interventions more broadly. Despite the increased attention on climate change mitigation and adaptation, most of the literature focuses on the physical science of climate change, conceptual issues and potential policies and frameworks related to mitigation and adaptation. To assess the current state of the literature we searched databases and websites to identify IEs of climate change interventions undertaken in developing countries. ${ }^{9}$ 
Apart from a few recent IEs in the conservation literature, the results of our searches were disappointing. It seems the application of rigorous IE techniques to assess the effectiveness of climate change interventions has so far been limited. This is also noted by a number of recent publications. For instance, Jones et al. (2008) find that there are significant gaps in the application of IE, and they particularly highlight the lack of studies on environmental protection, agriculture and health. Likewise, a recent desk review (Hedger et al. 2008) assessed the current state of climate change adaptation evaluations and found high-quality IEs lacking. Reviewing 11 evaluations of adaptation interventions in the GEF database, Hedger et al. (2008) note that evaluations generally depend on qualitative methods such as stakeholder interviews, tend to lack baselines, and are not integrated into projects.

An assessment of the evaluations of mitigation interventions included in the GEF database leads to similar conclusions: the evaluation methodologies are largely based on desk review, interviews and short field visits. White (2009c) also laments the lack of IEs of climate change mitigation interventions as this approach can be used to conduct cost-benefit analysis to assess the efficacy of investments. Moreover, noting the scarcity of counterfactual analysis in the related fields of biodiversity conservation and environmental economics more broadly, both Ferraro and Pattanayak (2006) and Greenstone and Gayer (2007) call for more widespread application of IE in these fields.

While there is a clear lack of rigorous IEs of climate change interventions, a few notable examples of IEs of conservation interventions stand out. These studies are focused on three types of interventions; namely, protected areas; payment for environmental services; and decentralised forest management. In the past these strategies have been applied to biodiversity and forest conservation, but they are also relevant for climate change interventions, most notably under the rubric of Reduced Emissions from Deforestation and Degradation and the conservation and sustainable management of existing forest carbon stocks (REDD+).

Protected areas have long been used for environmental conservation, and Andam et al. (2008), Gaveau et al. (2009) and Sims (2008) are recent examples of rigorous IEs of these policies in Costa Rica, Indonesia and Thailand, respectively. All three studies use matching techniques to construct a counterfactual and evaluate the impact of the protected area on avoided deforestation. While Gaveau et al. (2009) found the protected areas policy has not led to a complete halt in logging and deforestation in the intervention areas in Sumatra, all the three studies suggest a reduction of deforestation in protected areas. Moreover, the importance of using rigorous methods and controlling for potential sources of bias to avoid distorted estimates of impact is highlighted by a comparison with results obtained from other methods (Andam et al. 2008). Andam et al. (2008) estimate a substantially lower impact of protected areas on avoided deforestation in Costa Rica than estimated by conventional approaches, and suggest the lack of random allocation of protected areas, in addition to the lack of control for spillovers, as potential sources of bias in studies using conventional methods. In addition to evaluating the environmental impact of protected areas, Sims (2008) is a rare example of a study assessing impact on both environmental and development outcomes. Combining new consumption, poverty and inequality estimates from the sub-district level and remote sensing data on forest cover, Sims uses matching and regression techniques to estimate the impact of the protected areas on socioeconomic outcomes and land use. The results suggest that there are no causal links between the protected areas and the high poverty levels found in the communities nearby. Indeed, the analysis shows an increase in consumption and a reduction in poverty for those with land in national parks, although the distributional impacts of the protected areas may have been uneven.

Payment for environmental services (PES) programmes are another conservation policy where rigorous IEs are starting to emerge. Arriagada (2008), Pfaff et al. (2008) and Robalino 
et al. (2008) all evaluate the impact of Costa Rica's PES programme, while Uchida et al. (2007) evaluate China's land conservation programme, 'Grain for Green'. The PES programme in Costa Rica tries to reduce deforestation by providing forest owners with financial compensation for the services their forests provide. The 'Grain for Green' PES programme in China provides farmers with compensation in the form of grain, cash and seedlings if they set aside all or parts of their land to grow trees. The programme's primary objective is to avoid soil erosion by increasing forest cover, but further objectives also include poverty alleviation and sustainable agriculture.

To control for the non-random allocation of the PES programme, Pfaff et al. (2008) and Robalino et al. (2008) use both covariate and propensity score matching techniques to estimate the programme's impact on avoided deforestation, while Arriagada (2008) uses multivariate and propensity score matching. While Robalino et al. (2008) suggest there was a small increase in the avoided deforestation resulting from the PES programme in the 2000-2005 period, compared with 1997-2000, both studies of the PES programme in Costa Rica suggest the scheme has failed to have much impact on deforestation, and it is suggested this limited effect could be due to a significant reduction in deforestation across the whole country as a result of current and previous policies aimed at reducing deforestation. Hence, both studies argue that better targeting of the payments to areas with the highest risks of deforestation has the potential to improve the effectiveness of the programme (Pfaff et al. 2008, Robalino et al. 2008). Arriagada (2008) found little impact on forest loss, but found a small positive impact on forest re-growth and net deforestation. In China, Uchida et al. (2007) collected survey data on a randomly selected sample of 359 households, matching participants with non-participants using difference-in-difference estimation. The evaluation of 'Grain for Green' in China concluded the programme had been successful both in providing environmental services in the form of reduced soil erosion and in increasing the wealth of the mostly poor participants.

Lastly, decentralised forest management has become a widespread approach to forest conservation. Here we present two studies. First, Edmonds (2002) employed a pipeline approach and instrumental variable analysis to evaluate the impact of forest management by forest user groups in Nepal. National forest management was abandoned by the government in 1993 and field staff were instructed to start building forest user groups to manage forests without outside intervention. Three years later, over 4000 forest user groups had been established. As this included less than 10 per cent of Nepal's forests it enabled a comparison between areas with and without forest user groups. Thus, Edmonds (2002) matched data from a census of forest user groups in the Arun Valley with the location of communities included in Living Standards Measurement Survey data from the same area and estimated impact on fuel wood collection (as this is a major driver of deforestation in Nepal). The results showed that forest user groups reduced fuel wood extraction by around 14 per cent. Similarly, Somanathan et al. (2009) also employ a quasi-experimental design to evaluate the impact of decentralised forest management. This study used multiple regression analysis and propensity score matching to compare the impact and cost-effectiveness of the devolution of forest management to village councils from local government. The results suggest that village councils were at least as effective as local government in conserving forests. However, the expenditures by local government were more than nine times greater than village councils, leading the authors to conclude that 'substantial savings could be realized by decentralizing management' (Somanathan et al. 2009, p. 4146).

While there appear to be few IEs on behaviour change in support of climate change interventions, this is not to say that evaluations of the environmental impact of projects have not used counterfactual types of analysis. For example, there has been recent interest in increasing the use of scenario planning when conducting ex-ante environmental impact 
assessments (see Duinker and Greig 2007). Here, either quantitative techniques (such as cross-impact analysis, statistical modelling techniques or trend analysis) or qualitative approaches (such as Delphi techniques or horizon scanning) are used to define a baseline against which the impact of an intervention is judged (for a range of futures planning tools, see Ramalingam and Jones 2008). But this type of counterfactual analysis differs from IE: it utilises a constructed vision of a future baseline, in contrast to IEs concerned with utilising an actual or reconstructed control against which an intervention is judged.

While this brief review of existing IEs of environmental protection interventions in developing countries found some good examples of the application of quasi-experimental methodologies to evaluate conservation interventions, it is perhaps surprising that the application of rigorous IE techniques to climate change interventions has not become more widespread. With substantial volumes of finance necessary for climate change interventions in the coming decades, IE could play an important role in promoting the efficient use of these resources.

\subsection{The challenges of conducting IEs of climate change interventions}

Numerous reasons help account for the lack of rigorous IEs of climate policies. First, a number of common challenges faced by researchers when conducting IE are especially pronounced when attempting to evaluate environmental programmes. For instance, some programmes lack baseline data, include a long time lag between intervention and measurable impact (Chomitz 2008, Ferraro 2009, Hedger et al. 2008), lack an appropriate counterfactual for attribution (Chomitz 2008, Hedger et al. 2008), and include confounding factors and selection bias (Ferraro 2009). Adaptation interventions can be particularly challenging as they can include a diversity of interventions, and lack agreement on indicators and the definition of adaptation success (see Hedger et al. 2008).

Second, many climate policies are at a relatively early stage of implementation. For example, many adaptation initiatives have so far focused on governance and institutional processes not appropriate for IE designs (such as consultations, capacity building exercises, needs assessments and policy development). And third, Ferraro (2009) suggests that many environmental practitioners and scientists may lack experience in IE designs and methods.

This is not to say that counterfactual analysis has not been considered when evaluating climate interventions. For instance, the independent evaluation unit of the GEF has discussed the possible use of counterfactual analysis in evaluating some programmes (see Todd and Brann 2007). However, the challenges of conducting such evaluations, as highlighted above, the possible cost, as well as difficulties encountered when conducting a counterfactual evaluation of one energy efficiency programme, led Todd and Brann $(2007$, p. 9) to suggest that 'the rigorous impact evaluation model is neither appropriate nor affordable' for the GEF.

IEs of climate interventions can be a challenging undertaking, but that is not a compelling argument for not doing so. The examples of quasi-experimental evaluations of conservation programmes cited above illustrate that rigorous evaluation of environmental programmes are possible. Moreover, there are good reasons for pursuing them. As Ferraro argues:

Counterfactual thinking is critical to building the evidence base in environmental policy about what types of interventions work and under what conditions ... Despite the barriers and paucity of examples, there are substantial opportunities to elucidate causal relationships through experimental and quasi-experimental designs. (Ferraro 2009, p. 76) ${ }^{10}$ 
In addition, and as Greenstone and Gayer (2007, p. 42) note, estimating the costs and benefits of emission reductions on the basis of associational evidence 'can be highly misleading and can therefore lead to poor policies'. Triangulating such findings with studies that overcome selection bias problems and attribution issues is clearly desirable. The argument presented in this paper is that there appears to be a need to add to the existing evidence base.

In addition to the common challenges faced by researchers when conducting an IE, IEs of climate mitigation interventions are complicated because of difficulties in establishing baselines and measuring environmental outcomes. de Boer (2009) highlights how the lack of sufficient scientific capacity to measure the carbon sequestration in land use, land-use change and forestry (LULUCF) was one of the reasons for the exclusion of these sectors from the Kyoto Protocol. For example, for some mitigation interventions in the agriculture and forestry sectors, environmental outcomes will be highly dependent on the local environmental context (as the amount of carbon sequestered in the soil depends on climatic zone, local climatic conditions, characteristics of the soil, type of crop and cultivation practices; see Muller 2009). While progress has been made on addressing this issue, more work is needed, such as improving the measurement of carbon sequestration and emissions from modes of agricultural production (Muller 2009). ${ }^{11}$

An alternative approach to direct measurement of environmental outcomes is to use behavioural change as a proxy. In other words, to measure environmental outcomes in a smaller sub-sample of units and then use observation or survey data on behavioural outcomes, or modelling, to extrapolate the environmental outcomes for the larger sample (Conant and Paustian 2002, Ogle et al. 2007).

Similarly, Ferraro (2009) points out that measuring the intermediate impact on behavioural changes might be a more feasible approach when direct measurement of environmental outcomes is difficult. This approach could potentially be used for a wide range of mitigation interventions, especially those involving a shift away from carbon intensive technologies to alternative, tried and tested low-carbon technologies. Although when using proxy indicators one clearly needs to recognise that 'there may be a temporal aspect to their emergence; for example, positive behavioural outcomes might occur prior to the observation of positive ecological outcomes' (Brooks et al. 2005, p. 1529). In addition, as with all forms of evaluation, IEs need an explicit understanding of 'the shape of the impact trajectories associated with [an intervention's] projects, and . . how these trajectories vary for different kinds of projects operating in different contexts, at different scales and with varying degrees of implementation effectiveness' (Woolcock 2009, p. 1).

There is also a further set of challenges when conducting IEs of climate interventions: evaluations of climate mitigation measures in developing countries should ideally also assess impact on welfare. There are two good reasons for this. First, to ensure the mitigation efforts do not cause harm. And second, to maximise any adaptation co-benefits from mitigation actions. However, only two of the IEs reviewed in this paper measured both environmental and welfare outcomes (Uchida et al. 2007, Sims 2008). ${ }^{12}$

IEs of adaptation interventions will not always face the same challenges associated with measuring and establishing a counterfactual for environmental outcomes. Nevertheless, establishing a counterfactual for measuring people's capacity to adapt to and cope with the consequences of climate change can be problematic, especially if the intervention aims to reduce the risks associated with natural hazard events predicted to occur in the future (Dodman et al. 2009). However, the similarities between adaptation and conventional development activities means there is more experience to draw on: evaluators can use similar methodologies as those used in development evaluations (Hedger et al. 2008). 
Indeed, research by Adger et al. (2007, cited in Christoplos et al. 2009, p. 14) suggests indicators commonly used to measure human development have a statistically strong relationship with the ability to deal with climate-related events. ${ }^{13}$ Similarly, Hedger et al. (2008) suggest that many of the indicators used for measuring development effectiveness will also be related to adaptation and can be used to assess impact on adaptive capacity. They highlight the importance of building on existing indicator frameworks to avoid duplication of efforts and 'indicator overload'. ${ }^{14}$

As this discussion has illustrated, evaluators face numerous challenges in conducting IEs of mitigation, and, to a lesser extent, adaptation initiatives. They will have to work with environmental practitioners, scientists, development practitioners and social scientists to form creative solutions, while maintaining the rigour required for constructing a valid counterfactual (Ferraro 2009). Some of the mechanisms adopted in climate change interventions will be similar to those used to achieve other development objectives, and the increasing number of IEs in other policy fields can provide useful guidance for the design of IEs of climate change interventions. We now turn to examples of key mitigation and adaptation interventions. For each area of intervention, we discuss the potential for implementing IEs and, where possible, offer an example of a relevant completed IE study.

\section{Mitigation interventions}

\subsection{Green growth strategies}

International pressure to control carbon emissions is growing, with countries being encouraged to adopt 'greener growth paths' - in other words, to find ways to grow while controlling the associated increase in carbon emissions. Such policies are less likely to affect agrarian countries in sub-Saharan Africa than countries that are industrialising, such as China and India. Nevertheless, and as illustrated in the Copenhagen Accord, even countries with substantial 'ecological space' may voluntarily implement low-carbon growth policies, and tighter environmental standards and regulation. It is vital to ensure that these approaches do not undermine economic growth, but stimulate it through improved energy efficiency and productivity. ${ }^{15}$

In the past decade, reducing carbon emissions associated with economic growth has focussed on reducing the energy intensity of growth (World Bank 2008). A particular concern has been the inefficient production equipment in many industries in Eastern Europe and parts of Asia (World Bank 2008). ${ }^{16}$

Todd and Brann (2007) review studies assessing the extent to which energy efficiency measures reduced electricity consumption and GHG emissions in Thailand, Poland, Mexico and Jamaica. The studies found that energy-efficiency measures resulted in major changes in the residential market for lighting, refrigeration and air conditioning, especially in Thailand. Moreover, the studies also made some estimates of the costs and environmental benefits of the projects. Annual reductions of electricity sector emissions were estimated at around 0.5 per cent, with the exception of around 3.5 per cent reductions in the case of Thailand. Costs of around US\$1-5 per ton of carbon reduction were found in Thailand, Poland and Mexico; while at around US $\$ 40$ per ton, costs were much higher in Jamaica. Thus, in three of the four countries in the study, the benefits were estimated to exceed costs by a factor of between two and five. In Jamaica, the benefits were found to be only 40 per cent of costs. Overall, the measures were found to make a modest contribution to the integration of energy efficiency objectives into energy policies. 
However, these studies suffered from a number of shortcomings: IE was not integrated into projects at the outset, so the development of a comparison group was ex post and 'highly speculative', and the IE encountered resistance from project staff. Despite the considerable deficiencies of this project (including the difficulties of obtaining good data), it does illustrate that IE can be employed, especially when qualitative forms of enquiry are included to provide some estimates of the impact of energy-efficiency measures that are at the core of green growth strategies.

\subsection{Clean Development Mechanism}

The Clean Development Mechanism (CDM) was established by the Kyoto Protocol as a means to assist Annex I countries in achieving their emission reduction commitments and to contribute to low-carbon growth in non-Annex I countries (United Nations 1998). It provides one of three channels through which industries and companies within Annex I countries can augment their allotted emission amounts (the other two being the purchase of emission rights from other Annex I countries, or the purchase of emission-reduction credits from offset projects in Annex I countries). ${ }^{17}$ In short, the CDM enables industries or companies in Annex I countries to purchase Certified Emission Reductions from projects in developing countries on the condition that the reductions are additional to any GHG reductions that would have occurred without the CDM project.

Since the Kyoto Protocol came into force in 2005 (with 55 signatories accounting for at least $55 \%$ of 1990 emissions) the CDM has become a major offset market with over 1900 projects registered, and over 2500 and 280 at the validation and registration stages, respectively (Fenhann 2009). Over 60 per cent of CDM projects are in the renewable energy sector, such as hydropower or biomass energy schemes. However, industrial gas projects, where powerful GHGs such as hydrofluorocarbons or nitrous oxide are sequestered, account for over 70 per cent of the Certified Emission Reductions issued (due to the potency of these emissions). This is partly due to the restrictions on the inclusion of forestry and land-use change projects within the CDM (although afforestation and reforestation projects were included). ${ }^{18}$ However, this sector could play a much larger role in the CDM in the future as there was substantial progress in Copenhagen on integrating REDD+ into a global climate regime (see Phelps et al. 2010).

The geographical concentration of CDM projects remains extremely uneven: as of 1 November 2009, 78 per cent of projects in the CDM pipeline are in Asia and the Pacific (mainly in China and India), and 17 per cent in Latin America, with few projects in other regions of the globe (Fenhann 2009). There are a number of straightforward reasons for this spatial disparity: the more industrialised non-Annex I countries are able to clean up existing heavy industry; CDM projects contain large economies of scale (including substantial upfront costs for each project); and non-Annex I parties lack the financial resources and technical expertise to tackle high upfront costs and complex procedures, respectively (see Keane and Potts 2008).

While some recent work (Huang and Barker 2009) suggests that CDM projects have had a significant effect on emissions reductions in host countries, ${ }^{19}$ the effectiveness of the CDM in achieving its twin objectives of sustainable development and emissions reductions has also been brought into question (see Olsen 2007, Schneider 2007, Sutter and Parreño 2007). In particular, the effectiveness of the CDM in achieving additional emissions reductions has received widespread attention in the literature, especially regarding projects in China (Paulsson 2009, Michaelowa and Purohit 2007, Wara and Victor 2008).$^{20}$ As the CDM is an offset mechanism, the issue of additionality is of particular importance as a failure to 
reduce emissions compared against a 'business as usual' baseline can lead to a net increase in global emissions, as the purchasers buy the right to emit in their home country.

The CDM utilises a form of counterfactual analysis, although establishing convincing business-as-usual baselines is not straightforward for CDM project developers (see Paulsson 2009). A baseline is defined by the UNFCCC as 'the scenario that reasonably represents the anthropogenic emissions by sources of greenhouse gases that would occur in the absence of the proposed project activity' (UNFCCC 2006). These baselines can be constructed using one of three approaches: current or historical emissions; future emissions from an economically attractive course of action; and the average emissions from comparable projects implemented in the past five years when their performance is in the top quintile of their category (UNFCCC 2006). The first of these approaches uses a static before-versus-after comparison, and the second a constructed baseline scenario; the third utilises a comparison project to calculate reduced emissions.

As project developers benefit from inflating baseline figures, accredited firms validate and verify baseline scenarios and claimed emission reductions. These firms, commonly known as Designated Operational Entities, must utilise a UNFCCC-approved methodology for the sector in question: for example, energy, manufacturing, chemical, transport, waste, and afforestation/reforestation. Despite the use of control and treatment groups to assess some initiatives, our searches did not identify any IEs specifically on CDM projects (or at least the evaluations were not labelled IEs).

Experimental and quasi-experimental approaches are not well suited to assessing investments in large-scale investment in plant or infrastructure. Other techniques including structural modelling approaches such as computable general equilibrium models (widely applied to analyses of major policy initiatives such as trade policies; see Harrison and List 2004) might be more appropriate for evaluating the effectiveness of major policy interventions within the CDM. A review of the methodological and applied literature on structural modelling approaches to evaluation is beyond the scope of this paper, but it is worth noting that a number of recent studies of climate change policies use this technique - for example, Kallbekken (2006) and Sue Wing and Kolodziej (2009), which use computable general equilibrium modelling to provide ex-ante estimates of the impact of CDM and the Regional Greenhouse Gas Initiative in the United States, respectively. In other cases, pipeline approaches may offer a useful way of integrating IE into CDM assessments.

\subsection{Agriculture}

As agriculture is a major contributor of GHG emissions, recent studies have highlighted the potential for mitigation from this sector (Smith et al. 2007, World Bank 2007, de Boer 2009, FAO 2009a, 2009b). It has been estimated that around 74 per cent of emissions from agriculture originate in developing countries (FAO 2009c), and there have been calls to include incentives for emissions reductions in agriculture in developing countries within a future climate change treaty (World Bank 2007, FAO 2009b).

Mitigation options in agriculture include interventions that contribute to the reduction, removal and avoidance or displacement of emissions (Smith et al. 2007). The range of practices include organic and low-input agriculture, agro-forestry, restoration of degraded land, crop rotation, improved land and natural resource management, more efficient livestock production and capture and storage technologies for manure (Smith et al. 2007, World Bank 2007, Kranjac-Berisavljevic et al. 2009, FAO 2009c).

However, whilst it may be possible to accurately measure, report and verify the abatement of GHG emissions from agriculture in developing countries, we need to be cautious 
about whether there are good reasons to do so. Clearly, rural communities in developing countries have contributed least to GHGs in the atmosphere, and in this sense have some 'ecological space'. Moreover, we need to be keenly aware that the rural poor often, directly or indirectly, derive the majority of income from agriculture and that any mitigation measures must not reduce income or food security. The application of intensive agricultural practices has been one of the most effective forms of poverty reduction to date, as illustrated by the attempts of the Alliance for a Green Revolution in Africa (AGRA) to replicate the smallholder-led productivity gains achieved in Asia (for example, see Hazell and Ramasamy 1991, Rosegrant and Hazell 2000). In this respect, it is important to ensure that calls for organic and low-input agriculture in low income countries on the grounds of climate mitigation do not place a burden on the poor or harm developmental objectives. But that said, high-yielding seed varieties and high-input agriculture may not be the right approach in all places, and practices such as agroforestry, reduced tillage and agro-ecology are likely to be beneficial in some contexts. The challenge is to ensure that the right approach to increasing productivity is adopted in the right places by the right farmers. Thus, it is important that IEs of interventions to change agricultural practices are designed to assess both environment and human welfare outcomes.

With this important caveat in mind, the literature suggests two main reasons for the lack of progress in mitigating emissions from agriculture: first, a lack of appropriate financial mechanisms; and second, important technical issues regarding leakage, additionality, measurement, monitoring, reporting and verification (World Bank 2007, FAO 2009c). Whilst climate change mitigation in the agricultural sector is still at a very early stage, the Food and Agriculture Organisation suggests that one can accurately measure the role of agriculture to changes in soil carbon stocks by 'applying efficient sampling designs and rigorous protocols' (2009c, pp. 3-4). For example, through combining the direct measurement of soil carbon across an intensive sample of benchmark sites to evaluate the impact of different practices, with more diffuse sampling to assess the aggregate impact of an intervention on wider soil stocks (Conant and Paustian 2002).

The FAO (2009c) also proposes that combining direct field measurement with modelbased approaches could provide a cheaper alternative to intensive direct measurement. For instance, using a simulation model developed for ecosystem processes and data from 47 agricultural experiments, Ogle et al. (2007) test the relationship between modelled and measured carbon stock values under different production systems. They found a significant relationship between modelled and measured results (and developed a statistical model to adjust for biases and quantify the precision of the results).

Such an approach requires the establishment of a database with empirical data on carbon content in the soil from a range of pilots across agro-ecological zones, with information on soil, climate, land use and management. The FAO (2009c) suggest a coordinated effort to conduct and 'pool' direct measurements obtained following a rigorous protocol so that, in the future, practice-based performance standards can be used instead of the more expensive direct measurements.

While we are not aware of any IEs that assess the impact of agricultural mitigation strategies on wellbeing and environmental outcomes, there are a number of evaluations of interventions in agriculture that illustrate the possibilities for IE in this sector (for example, Feder et al. 2003). ${ }^{21}$ For instance, a recent study evaluates the impact of the adoption of sustainable agricultural practices, with special focus on reduced tillage (Kassie et al. 2009). The study also compares the productivity gains from reduced tillage to those resulting from chemical fertiliser use. Kassie et al. (2009) use propensity score matching and a switching regression framework to analyse plot-level survey data from two different agro-ecological 
zones in Ethiopia, a low rainfall area of the Tigray region and a high rainfall area of the Amhara region. They estimate the impact of fertiliser under different tillage regimes and the impact of tillage practices under different fertiliser regimes. The results from this analysis suggest reduced tillage had a significant positive impact on crop productivity in areas with lower rainfall, while chemical fertiliser had a greater significant positive impact in high rainfall areas. Thus, Kassie et al. (2009) conclude that, in a dry land environment, sustainable agricultural practices like reduced tillage can have multiple benefits for resource poor farmers by increasing yields, reducing production costs and promoting environmental benefits.

\subsection{Biofuel production}

Global demand for liquid biofuels more than tripled between 2000 and 2007 (Sims et al. 2008). Whilst biofuels are often couched in terms of reduced GHG emissions, production is also based on a desire for energy self-sufficiency in the face of recent spikes in oil prices (for example, the United States and EU set targets for biofuels within their transport energy mix). ${ }^{22}$ The need for mitigation and energy self-sufficiency suggest that demand for biofuels will continue to increase.

While 90 per cent of current global biofuel production is based in the United States, Brazil and the EU (mainly from cereals, maize, rape seed and sugarcane), biofuel production is also taking place in many developing countries (including second-generation biofuels produced from non-food materials such as wood, energy grass and other cellulosic biomass).

The switch towards second-generation biofuels is important because continued firstgeneration biofuel production is likely to impact negatively on global food availability and affordability. Both the reduced supply of staple food crops for consumption, and the increased competition for factors of production, may well contribute to higher global staple food prices with the poor worst affected (see Wiggins and Levy 2008). For example, Mitchell (2008) estimates that the most important factor behind the increase in global food prices between 2002 and 2008 was expanded biofuel production in the United States and EU. Such pressure on global prices looks set to stay despite farmers' supply response as it is profitable to use maize for ethanol production when oil prices are above $\$ 55$ per barrel (Piesse and Thirtle 2009). Despite current global economic difficulties, such a scenario appears likely in coming years if one considers the increased dominance of OPEC in the oil market, political instability in key exporting nations such as Iraq, Iran, Venezuela and Nigeria, and increased demand from China and other emerging economies (see Smith 2009).

There will also be winners and losers from biofuel cultivation in developing countries. Benefits are likely to accrue to developing country biofuel crop producers, including smallholder farmers by generating employment and increasing rural incomes (Peskett et al. 2007). However, major concerns are being raised about potential negative economic and environmental impacts from biofuel production (World Bank 2008). Firstly, some biofuels are not economically viable at current oil prices in the absence of subsidies, which means costs to tax-payers. Second, the production of biofuels in developing countries could reduce food availability and affordability in local markets. Third, biofuel production may not provide savings in GHG reduction; for example, in Indonesia the clearance of peat swamp forests for oil palm production is estimated to have been a major contributor to making Indonesia the third largest emitter of GHGs in 2006 (PT. Pelangi Energi Abadi Citra Enviro 2007). ${ }^{23}$ And fourth, biofuel crop cultivation may have serious costs in terms of loss of natural habitats; for example, many species being promoted for biofuel production, 
including jatropha curcas, have become invasive in countries where they have been introduced (World Bank 2008, p. 44). But to what extent has IE assessed the environmental and poverty effects of biofuel production?

Rajagopal and Zilberman (2007) review a number of studies examining the environmental implications of biofuels. They suggest that the impacts of biofuel production need to be evaluated on a case-by-case basis. For example, the net impact on GHGs associated with biofuel production depends on a number of context-specific factors, including: emissions associated with feed-stock cultivation; the biofuel production process; transport of biofuels to markets; and, importantly, changes in land use.

Rajagopal and Zilberman (2007) also note that little is known about the poverty impacts of biofuel production in developing countries. Again, a wide number of factors effect need to be considered here, including whether the poor are producing or working on the crop, the feedstock and production system, transport and institutional structures, existing crop production and processing regimes, labour requirements, security of land tenure, and the stability of prices (for a summary, see Peskett et al. 2007). Naturally, the net effect on poverty will vary across crops and countries, and as such biofuel production offers is in need of rigorous IEs.

One example of how IE could be used to assess biofuel production comes from Malawi (NASFAM, personal communication). NASFAM, the largest producer organisation in Malawi, is in the pilot phase of a project to promote smallholder jatropha curcas production amongst its smallholder farming clubs. Jatropha curcas thrives on poor and eroded soils and is now being increasingly used in reforestation programmes in tropical countries. It also has good potential as a second-generation biofuel. NASFAM is a farmer-directed business system based on the individual participation of close to 100,000 Malawian smallholders, most of them farming less than a hectare of land. Through its network of smallholder-owned business organisations, it develops the commercial capacity of its members and delivers programmes that enhance their productivity. NASFAM is considering using IE to compare 400 'grower' households in around 20 farming clubs, against a further 400 'non-grower' households acting as the control group. The primary purpose of the evaluation is to assess the extent to which jatropha production will increase and stabilise the incomes of smallholder farmers in Malawi. Of particular concern in this evaluation will be the food security impacts of jatropha adoption, and the relationship between jatropha production and hybrid maize production. The evaluation could help to determine the extent to which NASFAM supports jatropha production amongst its members.

\subsection{Forest carbon}

Climate change is leading to initiatives to preserve carbon held in tropical forests. High on the agenda and a key theme in current climate change negotiations is the proposal to integrate REDD+ into a global climate regime (for example, see Ebeling and Yasue 2008, Karsenty 2008, Neeff and Ascui 2009). It has been estimated that REDD initiatives could generate annual revenue flows of between US\$2.2 and 13.5 billion (Ebeling and Yasue 2008). REDD promoters also suggest that it could offer 'co-benefits' for the poor.

While the details of designing forest carbon schemes that provide co-benefits for the poor are complex, three issues stand out (Luttrell et al. 2007, Peskett and Harkin 2007, Peskett et al. 2007). First, the complexity of engaging in carbon markets means poor communities will often need to work through intermediaries, or brokers, such as nongovernmental organisations (NGOs), co-operatives and social movements. Second, the land and therefore carbon rights of the poor need to be assured if they are not going to be 
dispossessed. And third, carbon market contracts need to be designed in a clear, transparent and equitable fashion. Experiences of contract farming - where a firm lends inputs such as credit, fertiliser, seed and extension to a farmer, in exchange for exclusive purchase rights over the contracted crop - are instructive. Here, it is essential that state or non-state actors offer accessible, transparent and legally-binding mechanisms for dispute resolution between firms and farmers, if such contracts are going to work for both parties (Prowse 2007a).

In addition to the evaluations of PES interventions cited above, there are a number of planned and ongoing evaluations that provide examples of how rigorous evaluation designs can be applied to projects relevant to REDD+. For instance, Alix-Garcia et al. (2008) are studying the behavioural response of households and communities to the Payments for Hydrological Services programme in Mexico. They assess environmental effectiveness by comparing the deforestation rates of the properties enrolled in the programme in 2004 with those rejected for administrative reasons and those that applied in the following years, using data from newly interpreted high-resolution satellite images. Additionally, the study also measures deforestation spillovers to nearby areas to determine whether reduced deforestation on properties participating in the programme have displaced the surrounding areas. While this ongoing study is currently focusing on properties that entered the scheme in 2004, the team is hoping to extend the analysis to include multiple years. This proposed project in Mexico offers an illustration of the potential to use an experimental IE design to evaluate REDD+ interventions.

While still in the project preparation phase, a further example comes from Uganda (GEF 2008). While not strictly speaking a climate change intervention, the project - Developing an Experimental Methodology for Testing the Effectiveness of Payments for Ecosystem Services to Enhance Conservation in Productive Landscapes in Uganda - aims to 'test the effectiveness of PES as a viable means for financing and procuring biodiversity conservation outside protected areas using an experimental methodology' (GEF 2008, p. 1). The project attempts to determine the effectiveness of different payment arrangements for ecosystem services. It will offer payments to individual landowners in one treatment group, and payment at the community level or to local institutions in another. In doing so the project seeks to provide both social and environmental benefits. The project will include 12 randomly selected communities from a homogeneous region in Uganda identified as at risk of deforestation. The decision to use experimental design is motivated by the need for rigorous evidence of environmental interventions, and the project document states that 'a major aim of the project will be to successfully demonstrate this methodology to catalyze wider replication in the GEF portfolio' (GEF 2008, p. 5).

\subsection{Environmental labelling}

Responses to climate change have implications for two fast-growing exports - nontraditional agricultural products and tourism. Concerns about 'food miles' are leading to carbon-related labelling schemes (see Macgregor and Vorley 2006, Ellis and Warner 2007). For example, in early 2007 leading UK supermarkets introduced labelling schemes that could discourage the purchase of fruit and vegetables from countries such as Kenya and Ethiopia. One scheme, from Marks and Spencer, aimed to reduce the amount of air-freighted produce, and to label such items in stores. Another, by Tesco, aimed at reducing the company's carbon footprint by reducing air-freighted products by over 60 per cent, and labelling the remaining air-freighted goods (Garside et al. 2007).

Here we can clearly see the potential development versus environment trade-off in some climate change interventions. Over one million people in rural Africa rely, directly and 
indirectly, on fresh fruit and vegetables exports to the United Kingdom, and it is estimated that not buying fresh produce air-freighted from Africa would reduce UK emissions by less than 0.1 per cent (Ellis and Warner 2007). Since late 2007 both supermarkets have become more cautious in their approach to reducing air-freighted goods and to implementing such labelling schemes. Interestingly, both have indicated that such labels have had no discernable impact on sales (Garside et al. 2007). Similar concerns about developed country 'carbon footprint' could discourage holidaymakers from visiting countries such as South Africa, Namibia and The Gambia, from which the poor can accrue up to 15-35 per cent of total expenditure (see Mitchell et al. 2007).

As labelling schemes may be creating non-tariff barriers for exports from developing countries and could reduce market demand, it is clear that a more sophisticated labelling scheme - that takes into account the overall environmental impact, not just the air transport component, and that also factors in the development impacts of consumption decisions would be preferable (Ellis and Warner 2007). But how could this be realised? And what metrics should be used?

Garside et al. (2007) and Chi et al. (2009) highlight that if environmental harm is to be compared against poverty reduction or broader development goals, then schemes need to consider developing countries' 'ecological space' for carbon emissions, and quantify both the degree of harm from air-freighted produce or tourist flights and the poverty impact on individuals and households.

IE techniques can assess both the demand for such labelling schemes, and the impact they have on wellbeing in developing countries, as well as carbon emissions.

First, by randomising which products within a range of goods in supermarket outlets carry the 'air-freighted' label, it would be very simple to assess the extent to which consumers react to such labels, and whether there is substantial demand for them. As noted above, initial indications suggest that they have little impact on sales.

Second, IE could be used to assess possible impact on producers. Air-freighted goods are often produced on estates or by outgrowers (as they offer increased reliability of supply quantity and quality compared with spot markets or smallholder producers). Depending on the number of estates engaged, or the number of outgrower farmers, it may be possible to randomise the units where air-freighted goods are being labelled.

If it is possible to randomise in this manner, then a 'before and after' double difference IE could be conducted to assess one or more of the following research questions: the possible impact on the profitability of the estate/farm; the possible impact on the wellbeing of workers or smallholders; and estimates of the reduction in carbon emission caused by the 'airfreighted' label.

If it is the case that such labels reduce the profitability of firms and the wellbeing of poor workers, having quantitative data would strengthen the case for some compensatory mechanism (possibly financed by a price premium paid by consumers).

\section{Adaptation interventions}

Adaptation interventions are undertaken at different scales, across sectors and through different strategies. ${ }^{24}$ As with all fields, the type of intervention will have implications for how IEs are designed. This section provides a brief discussion of IEs of adaptation interventions in agriculture and water sectors, and when adaptation involves some form of social protection. The final section discusses a populist approach to tackling the effects of climate change: community-based adaptation. 


\subsection{Agriculture}

Current and predicted climate change means that adaptation in the agricultural sector is urgent (World Bank 2007). Farmers are already altering their practices in response to changes in the climate (Deressa et al. 2009), and poor people and countries will need outside assistance for adaptation (World Bank 2007). Poor farmers' ability to cope with stresses induced by climate change will depend, inter alia, on access to knowledge, training, credit and technologies (Kranjac-Berisavljevic et al. 2009). For example, the World Bank (2009a) outlines three strategic objectives for adaptation efforts in agriculture: monitor climate change impacts on crops, forests, livestock and fisheries; support farmers and lenders in managing the risks of climate change impacts; and improve management techniques and crop varieties/livestock breeds to prevent crop and livestock losses due to climate change and increased pest pressures (World Bank 2009a). Poor farmers' ability to adapt will also depend on their health and food security status, their ability to access labour markets, and opportunities to derive a greater proportion of income from non-climate-affected farm and non-farm sources (for example, see Sabates-Wheeler et al. 2008). Whether based on the application of improved technology, husbandry and capital markets, or interventions to support human capital and diversified livelihood portfolios, adaptation interventions in agriculture are likely to include elements that are similar to existing agricultural interventions. For example, many projects outlined in National Adaptation Plans are reminiscent of conventional rural development projects.

The AADAPT initiative by the World Bank shows how rigorous IEs of agricultural development and adaptation interventions can be structured (World Bank 2009c). At a recent meeting in Addis Ababa, a number of proposed evaluations were presented. Examples include an evaluation of the Rural Capacity Building Project in Ethiopia (Hiluf et al. 2009), the Ethiopia Nile Irrigation and Drainage Project (Tessema et al. 2009), the Agricultural Development Program Support Project in Malawi (Musopole et al. 2009), Market-led Smallholder Development in the Zambezi Valley in Mozambique (Banze et al. 2009), and the Impact of the Productive Safety Nets Project on Agricultural Productivity in Ghana (Dannson et al. 2009). All of these research projects propose to use experimental or quasi-experimental methods to evaluate agricultural interventions of relevance to climate change adaptation. For instance, Dannson et al. (2009) plan to randomly select districts for participation in the Productive Safety Nets Project on Agricultural Productivity in Ghana, and then randomly select four proposals from each district for funding in the first year. They will then compare agricultural productivity and household consumption among beneficiary and pipeline communities in order to evaluate impact. Similarly, Musopole et al. (2009) use an experimental design to evaluate three different methods of disseminating two different agricultural technologies of relevance to adaptation, namely conservation agriculture and fertiliser management. The evaluation of the Rural Capacity Building Project in Ethiopia faces a common problem for evaluators in that the treatment has already been assigned to the intervention units (Hiluf et al. 2009). However, the study utilises quasi-experimental methods to deal with this, using propensity score matching to construct the control group and difference-in-difference to estimate impact. As these evaluations are still in the early stages, there are not yet any results to report on. Nevertheless, they illustrate the feasibility of using IE methods to assess the impact of adaptation intervention in agriculture.

\subsection{Water resource management}

There is a wide spectrum of adaptation interventions to improve water management. These include increasing storage capacity by building reservoirs and dams, improving water 
supply, desalination and extraction of sea water, water recycling to improve water use efficiency, changes in agricultural practices to reduce the demand for irrigation, improving water conservation and watershed management, and protecting natural resources such as forests (Kundzewicz et al. 2007, World Bank 2009a).

As with all interventions, the choice of IE design depends on the intervention, but it is likely that both experimental and quasi-experimental approaches could be applicable to a range of adaptation interventions in this sector. Here we offer two examples: one regarding production (irrigation), and one on consumption (rural water supply). First, a recent study of two irrigation projects in Andhra Pradesh, India provides a useful example of an IE using quasi-experimental design to evaluate the impact of a large-scale infrastructure programme in the water sector (Independent Evaluation Group 2008b). While there were no baseline data and the project was closed when the evaluation was undertaken, as a number of farmers were yet to be connected to the system and were due to receive irrigated water in the 2005 and 2006 seasons, the study team adopted the 'pipeline approach', with the final group to be selected as the control group. Impact was estimated by applying difference-in-difference methodology to data from two survey rounds. While some of the predicted benefits failed to materialise and the projects suffered from delays and higher costs than was budgeted, the IE suggests access to irrigation leads to an increase in both yields and farm income. The study also assessed the effectiveness of participatory irrigation management, suggesting that while water user associations can contribute to water management, there is still need for government support, for instance to ensure equitable distribution and resolve disputes.

Turning to the supply of potable water, White (2006) briefly discusses the use of IE by the World Bank to assess three rural water supply projects in Paraguay through the 1980s and 1990s. Over US\$80 million was spent through the National Environmental Sanitation Service, which created over 400 community-level institutions - termed juntas de saneamiento - to operate and maintain the water distribution and delivery systems. An IE compared the wellbeing outcomes of five villages that had received clean and safe water from the project, and five villages that had not. Single-difference results (in other words, a static 'with versus without' comparison) highlight that villages with water had seven times fewer hospital visits than those without, and that morbidity, in particular diarrhoea and vomiting, was three or four times less frequent in villages with this improved water supply.

Importantly, the evaluation provided some figures on efficiency and equity. For example, the supply of clean water was often based on tariffs set below cost-recovery levels. Despite this subsidy, 10-15 per cent of the rural villagers had still not been able to connect to the water system. While reducing the subsidy would have reduced poor households' ability to access clean water, there was an important need for juntas to levy tariffs that enabled them to replace materials and infrastructure. Generating such figures are important if the costs and benefits of similar adaptation schemes are to be measured and incorporated into budgets and expenditure plans.

\subsection{Social protection}

Social protection is a broad concept that refers to public, private, formal and informal efforts to support communities, households and individuals in their efforts to prevent, manage and overcome vulnerability (CPRC 2008). Within the formal, public domain, it encompasses a range of interventions, including grants and insurance schemes, which support individuals from falling beneath a socially acceptable minimum standard of living. Examples include food aid, public works programmes, conditional and unconditional cash transfers as well as social insurance schemes for unemployment, old age and illness. Social protection is increasingly seen by development agencies and some developing country governments as 
an effective way to increase access to basic services and improve the wellbeing of poor households. The spread of conditional cash transfer programmes is testament to this.

One clear argument in favour of formal, public social protection is as follows. High levels of insecurity, whether based on environmental, market, socio-political or health risks, can have both immediate and longer-term repercussions for people's income and wellbeing (see de Janvry et al. 2006, Vakis 2006, CPRC 2008). People respond to such shocks, or the expectation of such shocks, in a variety of ways, including through selling off productive assets, taking loans, reducing consumption and withdrawing children from school (de Janvry et al. 2006, Vakis 2006, UNDP 2007, Andersson et al. 2009). Such short-term responses can lead to long-term detrimental impacts on poverty and human development. One of the central objectives of social protection programmes is to prevent such behaviour (UNDP 2007). IEs have played an important role in demonstrating that such programmes help promote long-term human development objectives (for example, Gertler 2000, Schultz 2004, Attanasio et al. 2005).

Social protection and social assistance/transfers are also now being seen as an effective adaptation strategy (Anderson et al. 2009, Commission on Climate Change and Development 2009, Oswald 2009, UNDP 2007). A range of different social protection instruments can promote adaptation and increase people's capacity to manage risk and cope with shocks. Examples include contributory insurance schemes designed to pool risks, cash transfers targeting vulnerable groups, social funds, service fee waivers, public works programmes and cash transfers for agricultural productive inputs in the aftermath of a shock (see Vakis 2006, UNDP 2007). While more evidence is needed on the impact of social protection interventions on adaptation, IEs of existing schemes demonstrate both the potential effectiveness of such interventions and the possibilities of using experimental or quasi-experimental approaches to evaluate their impact (see Gertler 2000, Schultz 2004, Attanasio et al. 2005). Indeed, de Janvry et al. (2006) and Andersson et al. (2009) evaluate two different social protection programmes and assess whether they protect the beneficiaries from shocks. ${ }^{25}$ de Janvry et al. (2006) utilise experimental panel data from the evaluation of the PROGRESA conditional cash transfer programme in Mexico to assess whether the programme protected children from the impacts of shocks. The results indicate that 'the Progresa transfers largely or completely protected children from the effect of these shocks on school enrolment' (de Janvry et al. 2006, p. 372). While the programme was not sufficient to avoid an increase in child employment in response to shocks, the analysis suggests the conditional cash transfer prevented this employment from crowding out schooling. Andersson et al. (2009) use a quasi-experimental design to evaluate the impact of the Productive Safety Net Program in Ethiopia, a public works programme targeting the food insecure. Employing household survey panel data analysis using matching techniques, they assessed whether the programme protects households' livestock and tree holdings during a period of insecurity and uncertainty. While they found the programme appeared to contribute to an increase in tree holdings, there was no evidence that it protected household's livestock holdings. These and many other evaluations show how IE techniques are able to assess the efficacy of social protection interventions in shielding individuals and households from insecurity and risk - a vital part of adaptation to climate change.

\subsection{Community-based adaptation}

Community-level adaptation (CBA) is an autonomous, bottom-up approach to adaptation, based on the premise that, through participatory learning and action, communities are best able to identify, prioritise and implement climate change adaptation (see Ayers and Forsyth 
2009). CBA builds on the technical knowledge and coping strategies of individuals and communities (for example, see Bharara and Seeland 1994, Mendelsohn and Dinar 1999, Mortimore and Adams 2001, Chatterjee et al. 2005). CBA is often facilitated by a wellknown local organisation, and can be implemented like a small-scale development project. A number of key principles have guided early CBA practice (Huq and Reid 2007). First, outside agencies must gain the trust of communities through immersed in the field and through using brokers and intermediaries (such as local NGOs or community groups). Second, possible future adaptation initiatives must be embedded in communities' existing knowledge of climate variability, and must be based on community members' participation. Third, community-based adaptation is a form of action research, and can only be learnt through practice. Fourth, experiences from pilot activities should be shared and collated. Fifth, the involvement of women is paramount. And sixth, communicating the concept of climate change should be in the vernacular and use a wide range of communication channels including art, theatre of video. However, whilst popular amongst NGOs, CBA has been subject to growing critique. For example, Sabates-Wheeler et al. (2008) suggest that CBA needs to engage much more seriously with the literature on livelihood and income diversification. $^{26}$

Moreover, framing folk wisdom, technical knowledge and coping strategies as CBA is relatively new, and therefore little attention has been paid to how it could be evaluated. At first glance, the bottom-up participatory emphasis of CBA suggests that it might not be well suited to IE techniques. For example, there appears to be some incongruence between the participatory action research approach of CBA and the positivist methodology utilised by experimental evaluation approaches (for example, see Prowse 2007a). Despite this tension, there may be some scope for IE approaches within CBA activities.

For example, if CBA activities are conducted through pre-existing self-help groups or farming clubs, which are supported by local institution such as a NGO or co-operative, then during a pilot phase when CBA is rolled out across a district or region, clubs (or even villages) could be randomised, allowing for a simple 'with or without' comparison of the intervention.

Unusually, because the actual practices stemming from CBA will be different across groups/clubs/villages (for example, improved tilling methods might be a focus in one group, whilst reforestation might be the priority in another) such a 'with or without' comparison could not evaluate particular activities. Instead, IE could evaluate the principle of CBA as a whole. Hypothetically, such an IE could shed light on whether CBA improves asset holdings and resilience to shocks. However, to elucidate how and why CBA led to improved resilience the IE would need to incorporate qualitative and participatory methods.

Whilst not strictly a CBA initiative, an example of how IE could be applied to CBA is given by the Watershed Organisation Trust in Maharashtra, India. In Maharashtra, on the western coast of India, agriculture is particularly prone to variable patterns of monsoon rainfall. With most of the rural population dependent on arid or semi-arid land, making the most of the available precipitation is vital to lives and livelihoods.

From the early 1990s, the Watershed Organisation Trust (WOTR) was established to provide support to self-help groups and local NGOs in water management techniques. The aim has been to focus of micro-catchments with the creation of village self-help groups. These groups guided and implemented improvements to local watersheds. Many of the measures in the scheme have been conducted in a bottom-up, participatory manner, with examples including:

- planting trees and grasses to improve waterways and to provide fodder and fuel;

- reducing tree felling and grazing to regenerate the local ecology; and 
- small-scale water barriers to reduce surface run-off, encourage the replenishment of aquifers, and reduce erosion.

The scheme also encouraged the uptake of new agricultural practices, and support to nonfarm livelihood activities. Due to the centrality of women to agriculture and environmental management in Maharashtra, the success of these measures has been determined to a large extent by women's commitment and engagement. Moreover, the community-driven participatory approach fostered a strong sense of ownership and control through the creation of village-level institutions.

In the past 15 years, the WOTR has boosted agricultural production and increased resilience to drought in over 150 watersheds encompassing over 160,000 hectares. The WOTR now contributes to state-level and national-level dialogues in community-based watershed management (International Institute for Sustainable Development 2003).

\section{Conclusion}

This paper gives an overview of the extent to which IE could be utilised in assessing the impact of climate change interventions in developing countries. It has highlighted an apparent lack of rigorous IEs of behaviour change to support climate change interventions. Apart from a few quasi-experimental evaluations in the related field of conservation, the application of IE to climate change interventions has been limited. Moreover, only two of these studies included estimates of both environmental and welfare outcomes (Uchida et al. 2007, Sims 2008). While in many cases evaluating climate change interventions are challenging, this is not a valid argument for not doing so. If calls for increasing financing of climate change mitigation and adaptation by hundreds of billions a year are to remain credible and gain support, evidence of the effectiveness of current spending is essential. Moreover, donors are likely to remain hesitant in providing additional funding unless it is clear that interventions are reaching their environmental and developmental objectives. As current funding falls far short of recent estimates of what will be required, evidence from IEs is essential to determine which adaptation and mitigation interventions are the most costeffective.

As many climate interventions are at an early stage of implementation, this is an opportune time for planners and evaluators to integrate IE designs from the start (when appropriate and affordable). Importantly, new studies should evaluate the positive and negative impacts of climate change interventions on both environmental and welfare outcomes. While appropriate outcome indicators will differ between interventions, future evidence syntheses will be improved by working to develop a consensus on a set of common or comparable outcome indicators at an early stage.

\section{Acknowledgements}

The authors thank Jennifer Alix-Garcia, David Barton, Anuapam Khanna, Malgosia Madajewicz, Ben Ramalingam, Katharine Sims, Jos Vaessen, Hugh Waddington, Rob van den Berg and Howard White for review and useful advice and comments on earlier drafts. The authors are responsible for all remaining errors. They are also grateful to Katharine Sims and Esther Mwangi for sharing details on the ongoing study in Mexico and the proposed evaluation in Uganda, respectively, and also thank Paul Ferraro for useful guidance on references. Thanks are also due to participants at presentations at the Global Development Network (GDN), New Delhi and at the Centre for Interdisciplinary Environmental and Social Research (CIENS), Oslo. The views contained in this report are those of the authors and do not necessarily reflect the views of 3 ie. 


\section{Notes}

1. In practice there may be some overlap between these two types of interventions, notably in sectors like agriculture and forestry (see Dodman et al. 2009). However, as the main aims of mitigation and adaptation interventions are different, we discuss the possible role of IE in assessing interventions separately.

2. The terms 'developing countries' and 'non-Annex I countries' are treated as synonyms, as are the terms 'developed countries' and 'Annex I countries'.

3. The UNFCCC defines a sink as 'any process, activity or mechanism which removes a greenhouse gas, an aerosol or a precursor of a greenhouse gas from the atmosphere' (United Nations 1992, p. 4). Examples of sinks include the forests, ocean, peat, permafrost and soil (IETA n.d). Sinks can be preserved or enhanced to increase their role in reducing GHG emissions to the atmosphere.

4. Includes other GHGs such as methane and nitrous oxide.

5. For transport, mitigation options are relatively limited because of dependence on oil as a fuel (although alternatives include fuel-cell vehicles, hydrogen power and biofuels).

6. For example, initial attempts at adaptation appear to have been planned using large-scale modelling to inform policy choices, whilst more recent approaches are based on communitybased activities that emphasise the existing coping strategies of communities and individuals (Huq and Reid 2007). This has led to calls that 'approaches to adaptation must be turned upside down to focus on local adaptation strategies as the point of departure for engagement' (Christoplos et al. 2009, p. 31).

7. Examples of specific adaptation interventions in the GEF portfolio include sustainable management of water resources in Argentina, market-led small holder development in Mozambique, adaptation using agro-biodiversity in Yemen, participatory coastal zone restoration in Sri Lanka, and piloting of community-based adaptation in ten different countries (GEF 2007).

8. The multi-tier framework presented by Ostrom (2007) can provide a useful starting point for theory-based IEs of climate change interventions and suggests a range of different variables researchers might want to consider when designing IEs.

9. We limited our attention to studies estimating impact using counterfactual analysis, based on the techniques discussed Section 3.1, and did not review studies using structural modelling techniques. We used keyword combinations such as climate change AND evaluation, clean development mechanism AND evaluation, climate change AND mitigation, climate change AND adaptation, 'payment for environmental services', 'risk management' AND environment AND evaluation, 'disaster risk reduction' AND evaluation, 'crop insurance' AND evaluation. Our sources included Google and Google scholar, Science Direct, JOLIS, IDEAS and BLDS. The Cochrane and Campbell Collaboration libraries were searched using the keywords climate change OR clean development mechanism and all results including any of these keywords were scanned. The websites of various organisations, such as the GEF, IIED, UNEP and J-PAL, were also searched and screened for any relevant results.

10. Ferraro (2008) lists four elements that are required for a study of the impact of protected areas on welfare to be credible in attributing effects to the intervention: indicators of human welfare at a relevant unit of analysis (for example, individual, household, community and region) that can be objectively measured; data on applicable indicators before and after establishment of the protected area (if baseline observations are not available another way of controlling for the initial situation and trends in social welfare has to be established); observations of the relevant indicators from treatment and control groups with similar characteristics; and observations of characteristics affecting location of protected areas and human welfare trends in both groups before the establishment of the protected areas.

11. A systematic review entitled 'Comparison of methods for the measurement and assessment of carbon stocks and carbon stock changes in terrestrial carbon pools' (Petrokovsky et al. 2009) is under preparation, and its findings should provide an important resource to evaluators of LULUCF interventions.

12. Vice versa, it is also important that development projects assess GHG emissions. The announcement that the World Bank and other multilateral development banks intend to assess the carbon footprint of future projects and are developing a common methodology for doing so improves the prospects that development projects will measure GHG emissions (Block 2009).

13. Adger et al. (2007, cited in Christoplos et al. 2009, p. 14) identify the following 18 indicators: population with access to sanitation; literacy rate, five to 14 year olds; maternal mortality; literacy 
rate, over 15 years; calorific intake; voice and accountability; civil liberties; political rights; life expectancy at birth; government effectiveness; literacy ratio (female-to-male ratio); Gross Domestic Product per capita; Gini coefficient; regulatory quality; rule of law; health expenditure per capita; educational expenditure as a percentage of Gross Domestic Product; and percentage of population employed in agriculture.

14. The Disaster Risk Index (UNDP 2004) and the Indicators of Disaster Risk and Risk Management (Cardona 2007) are examples of other existing tools evaluators can draw on when evaluating adaptation.

15. Green growth strategies could be beneficial to the poor as well as to the environment if they support a shift to low-polluting, labour-intensive production methods, and if they improve energy efficiency and stimulate growth.

16. A recent report from the Independent Evaluation Group (2008a) of the World Bank argued that rural electrification shifts energy use to more efficient and usually more sustainable sources, and suggested there is great scope for investments to reduce system losses that will greatly reduce the energy intensity of growth. The World Bank-supported off-grid energy supply contributes to carbon emissions reductions as the majority of the projects rely on renewable energy technologies and replace non-renewable energy sources. However, as the report highlighted, there is a need for further analyses of the environmental impacts of grid extensions.

17. The Kyoto Protocol stipulates that emissions reductions from CDM project activities must provide '[r]eal, measurable and long-term benefits related to the mitigation of climate change' and ' $[r]$ eductions in emissions that are additional to any that would occur in the absence of the certified project activity' (United Nations 1998, p. 12).

18. The eligibility of land use, land-use change and forestry projects under the CDM was one of the most controversial issues at the Sixth Conference of the Parties in November 2000. Thus only afforestation and reforestation projects were included in the CDM, with measures to address issues around non-permanence, social and environmental effects, leakage and additionality.

19. Huang and Barker (2009) reach this conclusion after estimating an environmental Kuznets curve by applying VAR (vector auto regression) modelling to panel data from 34 host countries for the period 1990-2007. However, as no method is used to control for selection bias, it is possible that this study provides evidence of an associational, rather than causal, nature.

20. There are different ways of assessing additionality under the CDM. The CDM's methodological tool for assessing additionality includes a four-step approach for identifying alternatives to the project that are consistent with current regulation, investment analysis, barrier analysis and common practice analysis. See CDM Executive Board (2008) for details.

21. IE of related interventions, such as protected areas and payment for environmental services, also provide useful examples that evaluations of mitigation interventions in agriculture can draw on.

22. The EU is aiming for 10 per cent of transport fuels to come from biofuels by 2020 , a substantial increase from the 3 per cent currently met through domestic production.

23. Moreover, Searchinger et al. (2008) argue that biofuel production from maize in the United States in recent years has not reduced GHG emissions since land-use change was not incorporated in the emissions calculations.

24. Hedger et al. (2008) and McGray et al. (2007) distinguish between three types of adaptation interventions: serendipitous adaptation - development activities that contribute to adaptation without being designed to do so; mainstreaming or climate proofing of development efforts - this includes changing the design of ongoing development activities or designing development interventions so that they are also successful in a changing climate (McGray et al. 2007); and discrete adaptation - activities specifically designed to address climate change and where adaptation is the primary objective, although common development strategies might still be applied.

25. An ongoing study by Marta Vicarelli is also using data from PROGRESA in Mexico, and combines these with data on local climatic conditions to assess the impact of local climatic varaiabilities on household consumption and the extent to which PROGRESA reduces vulnerability in the case of climatic shocks (available from: http://www.hks.harvard.edu/ centers/cid/programs/sustsci/people/research-fellows/current-fellows/marta-vicarelli).

26. Sabates-Wheeler et al. (2008) outline three main ways in which the livelihoods literature could improve CBA practice. First, it appears that CBA commonly assumes that localised livelihood diversification is a useful risk-spreading strategy, thus contributing to adaptive capacity. But local diversification within local farm-based or non-farm activities may increase risk. For example, 
climatic threats may be so severe that all households and local livelihood strategies are affected. In this respect, the approach could pay more attention to non-local strategies, such as migration. Second, Sabates-Wheeler et al. (2008) suggest that the approach has tended to homogenise the poor, not recognise different groups of poor people (for example, the chronically poor versus the transient poor), and not tailor adaptation strategies appropriately. And third, they suggest that the approach does not recognise that the ability to diversify into profitable non-farm activities is not wealth-neutral.

\section{References}

3ie - International Initiative for Impact Evaluation, 2008. Founding document for establishing the International Initiative for Impact Evaluation 3ie. 25 June. Available from: http://www.3ieimpact. org/doc/3ieFoundingDocument30June2008.pdf [Accessed 14 July 2009].

Adger, N., Arnella, W.M. and Tompkins, E.L., 2005. Successful adaptation to climate change across scales. Global environmental change, 15 (2), 1577-1586.

Adger, N., et al., 2003. Adaptation to climate change in the developing world. Progress in development studies, 3, 179-195.

Adger, N., et al., 2009. Are there social limits to adaptation to climate change? Climatic change, 93, $335-354$.

Adger, W.N., et al., 2007. Assessment of adaptation practices, options, contraints and capacity. In: M.L. Parry et al., eds. Climate change 2007: impacts, adaptation and vulnerability. Contribution of Working Group II to the fourth assessment report of the Intergovernmental Panel on Climate Change. Cambridge: Cambridge University Press, 717-743.

Alexander, D., 2008. Climate change and global social justice. Foreign Policy Centre annual lecture. 6 February. London School of Economics.

Alix-Garcia, J., Shapiro, J.M. and Sims, K.R.E., 2008. Learning from Mexico's payments for ecosystem services program. Draft proposal to the GEF.

Andam, K.S., et al., 2008. Measuring the effectiveness of protected area networks in reducing deforestation. Proceedings of the National Academy of Sciences, 105 (43), 16089-16094.

Anderson, K. and Bows, A., 2008. Reframing the climate change challenge in light of post-2000 emission trends. Philosophical transactions of the Royal Society, A, 366, 3863-3882.

Anderson, S., Geoghegan, T. and Ayers, J., 2009. An assessment of channels to support adaptation by the poorest. IOP conference series: earth and environmental science, $6,1-4$.

Andersson, C., Mekonnen, A. and Stage, J., 2009. Impacts of the Productive Safety Net Program in Ethiopia on livestock and tree holdings of rural households. Environment for development discussion paper series EfD 09-05. March. Washington, DC: Environment for Development Initiative and Resources for the Future.

Arriagada, R.A., 2008. Private provision of public goods: applying matching methods to evaluate payments for ecosystem services in Costa Rica. Dissertation (PhD). North Carolina State University, Raleigh.

Attanasio, O., et al., 2005. The short-term impact of a conditional cash subsidy on child health and nutrition in Colombia. Report summary: Familias 03, Centre for the Evaluation of Development Policies. London: Institute for Fiscal Studies.

Ayers, J. and Forsyth, T., 2009. Community-based adaptation to climate change: strengthening resilience through development. Environment, 51 (4), 22-31.

Bamberger, M. and White, H., 2007. Using strong evaluation designs in developing countries: experiences and challenges. Journal of multidisciplinary evaluation, 4 (8), 58-73.

Banze, O., et al., 2009. Mozambique - market-led smallholder development in the Zambezi Valley. Presented at the Cross-Country Workshop for Impact Evaluations in Agriculture and Community Driven Development, Addis Ababa, 13-16 April.

Barker, T., et al., 2007. Technical summary. In: B. Metz et al., eds. Climate change 2007: mitigation. Contribution of Working Group III to the fourth assessment report of the Intergovernmental Panel on Climate Change. Cambridge: Cambridge University Press.

Bharara, L.P. and K. Seeland, 1994. Indigenous knowledge and drought in the arid zone of Rajasthan: weather prediction as a means to cope with a hazardous climate. Internationales Asienforum, 25 (1/2), 53-71.

Birckmayer, J.D. and Weiss, C.H., 2000. Theory-based evaluation in practice: what do we learn? Evaluation review, 24 (4), 407-431. 
Block, B., 2009. World Bank initiates carbon footprint analysis. World Watch Institute. Available from: http://www.worldwatch.org/node/6209 [Accessed 25 November 2009].

Brooks, N., Adger, W.N. and Kelly, P.M., 2005. The determinants of vulnerability and adaptive capacity at the national level and the implications for adaptation. Global environmental change Part A, 15 (2), 151-163.

Burton, I., Diringer, E. and Smith, J., 2006. Adaptation to climate change: international policy options. Arlington: Pew Center on Global Climate Change.

Cardona, O.D., 2007. Indicators of disaster risk and risk management - program for Latin America and the Caribbean, summary report. Washington, DC: Inter-American Development Bank.

CDM Executive Board, 2008. Methodological tool - tool for the demonstration and assessment of additionality. Version 05.2, UNFCCC/CCNUCC, EB 39 Report. Bonn: UNFCCC.

Chatterjee, K., Chatterjee, A. and Das, S. 2005. Community adaptation to drought in Rajasthan. IDS bulletin, 36 (4), 33-52.

Chen, S., Mu, R. and Ravallion, M., 2006. Are there lasting impacts of a poor-area development program? Draft paper, Development Research Group. Washington, DC: World Bank.

Chi, K.R., MacGregor, J. and King, R., 2009. Fair miles: recharting the food miles map. Big ideas in development series. London and Oxford: International Institute for Environment and Development and Oxfam.

Chomitz, K., 2008. Challenges in climate evaluation. Presentation at the International Conference on Evaluating Climate Change and Development, Alexandria, Egypt, 10-13 May.

Christoplos, I., et al., 2009. The human dimension of climate adaptation: the importance of local and institutional issues. Background paper to the Commission on Climate Change and Develoment. Stockholm: Ministry of Foreign Affairs, Commission on Climate Change and Development.

Chronic Poverty Research Centre, 2008. The chronic poverty report 2008-09: escaping poverty traps. Chronic Poverty Research Centre, Brooks World Poverty Institute, University of Manchester.

Cline, W.R., 2007. Global warming and agriculture: new country estimates show developing countries face declines in agricultural productivity. Center for Global Development brief. September. Washington, DC: Center for Global Development.

Commission on Climate Change and Development, 2009. Closing the gaps. Stockholm: Commission on Climate Change and Development, Ministry of Foreign Affairs.

Conant, R.T. and Paustian, K., 2002. Spatial variability of soil organic carbon in grasslands: implications for detecting change at different scales. Environmental pollution, 116, S127-S135.

Cook, T.D., 2000. The false choice between theory-based evaluation and experimentation. New directions for evaluation, 87, 27-34.

Dannson, A., et al., 2009. Ghana - impact of the productive safety nets project on agricultural productivity. Presented at the Cross-Country Workshop for Impact Evaluations in Agriculture and Community Driven Development, Addis Ababa, 13-16 April.

Dasgupta, S., et al., 2007. The impact of sea level rise on developing countries: a comparative analysis. Policy research working paper 4136. Washington, DC: World Bank.

de Boer, Y., 2009. UNCCD Land Day: address by Yvo de Boer. Executive Secretary United Nations Framework Convention on Climate Change, Bonn, 6 June.

de Janvry, A., et al., 2006. Can conditional cash transfer programs serve as safety nets in keeping children at school and from working when exposed to shocks? Journal of development economics, 79, 349-373.

Dell, M., Jones, B.F. and Olken, B.A., 2009. Climate shocks and economic growth: evidence from the last half century. Available from: http://isites.harvard.edu/fs/docs/icb.topic607848.files/ Benjamin\%20Jones\%20Paper.pdf [Accessed 25 October 2009].

Deressa, T.T., et al., 2009. Determinants of farmer's choice of adaptation methods to climate change in the Nile Basin of Ethiopia. Global environmental change, 19, 248-255.

Dodman, D., Ayers, J. and Huq, S., 2009. Building resilience. In: World Watch Institute, ed. 2009 State of the world: into a warming world. Washington, DC: World Watch Institute, 151-168.

Duinker, P. and Greig, L.A., 2007. Scenario analysis in environmental impact assessment: improving explorations of the future. Environmental impact assessment review, 27, 206-219.

Ebeling, J. and Yasue, M., 2008. Generating carbon finance through avoided deforestation and its potential to create climatic, conservation and human development benefits. Philosophical transactions of the Royal Society for Biological Sciences, 363, 1917-1924.

Edmonds, E.V., 2002. Government-initiated community resource management and local resource extraction from Nepal's forests. Journal of development economics, 68, 89-115. 
Ellis, K. and Warner, M., 2007. Is the time ripe for a good for development product label? ODI briefing paper. London: ODI.

FAO, 2007. Adaptation to climate change in agriculture, forestry and fisheries: perspectives, framework and priorities. Rome: Interdepartmental Working Group on Climate Change.

FAO, 2008. Climate change and food security: a framework document. Rome: Food and Agriculture Organisation.

FAO, 2009a. Low greenhouse gas agriculture - mitigation and adaptation potential of sustainable farming systems. Rome: Food and Agriculture Organisation of the United Nations.

FAO, 2009b. Anchoring agriculture within a Copenhagen agreement - a policy brief for UNFCCC parties by FAO. Rome: Food and Agriculture Organisation of the United Nations.

FAO, 2009c. Enabling agriculture to contribute to climate change mitigation - a submission by the Food and Agriculture Organization of the United Nations. February. Available from: http:// unfccc.int/resource/docs/2008/smsn/igo/036.pdf [Accessed 10 July 2009].

Feder, G., Murgai, R. and Quizon, J.B., 2003. Sending farmers back to school: the impact of farmer field schools in Indonesia. World Bank policy research working paper 3022. Washington, DC: World Bank.

Fenhann, J., 2009. The Pipeline. UNEP Risø CDM/JI pipeline analysis and database. UNEP Risø Centre. Available from: http://cdmpipeline.org/ [Accessed 22 June 2009].

Ferraro, P.J., 2008. Protected areas and human well-being. Paper presented at the Economics and Conservation in the Tropics: A Strategic Dialogue Conference, San Francisco, 31 January-1 February.

Ferraro, P.J., 2009. Counterfactual thinking and impact evaluation in environmental policy. New directions for evaluation, 122, 75-84.

Ferraro, P.J. and Pattanayak, S.K., 2006. Money for nothing? A call for empirical evaluation of biodiversity conservation investments. PLoS biology, 4 (4), 482-488.

Financial Times, 2009. Interactive graphic: carbon emissions past and projected. Available from: http://www.ft.com/cms/s/d0940004-c7d5-11de-8ba8-00144feab49a,Authorised=false.html?_i_ location $=$ http $\% 3 \mathrm{~A} \% 2 \mathrm{~F} \% 2 \mathrm{Fwww}$.ft.com\%2Fcms $\% 2 \mathrm{Fs} \% 2 \mathrm{~F} 0 \% 2 \mathrm{Fd} 0940004-\mathrm{c} 7 \mathrm{~d} 5-11 \mathrm{de}-8 \mathrm{ba} 8$ 00144feab49a.html\&_i_referer=http\%3A\%2F\%2Fwww.ft.com\%2Fmultimedia\%2Finteractive [Accessed 15 December 2009].

Fischer, G., Shah, M. and van Velthuizen, H., 2002. Climate change and agricultural vulnerability. Report prepared for the World Summit on Sustainable Development. Vienna: International Institute for Applied Systems Analysis.

Garside, B., MacGregor, J. and Vorley, B., 2007. Miles better? How 'fair miles' stack up in the sustainable supermarket. IIED Sustainable Development Opinion. December. London: International Institute for Environment and Development.

Gaveau, D.L.A., et al., 2009. Evaluating whether protected areas reduce tropical deforestation in Sumatra. Journal of biogeography, 36, 2165-2175.

GEF, 2007. GEF - financing adaptation action. Washington, DC: Global Environment Facility.

GEF, 2008. Project Identification Form (PIF) - project type: medium-sized project. The GEF Trust Fund. Washington, DC: Global Environment Facility.

Gertler, P., 2000. Final report: the impact of Progresa on health. Washington, DC: International Food Policy Research Institute.

Greenstone, M. and Gayer, T., 2007. Quasi-experimental and experimental approaches to environmental economics. Discussion paper RFF DP 07-22. Washington, DC: Resources for the Future.

Hammhill, A., Matthew, R. and McCarter, E., 2008. Microfinance and climate change adaptation. IDS bulletin, 39 (4), 113-122.

Harrison, G.W. and List, J.A., 2004. Field experiments. Journal of economic literature, 42 (4), $1009-1055$.

Hazell, P. and Ramasamy, C., 1991. The green revolution reconsidered: the impact of high-yielding rice varieties in South India. Baltimore, MD: John Hopkins University Press.

Hedger, M.M., et al., 2008. Desk review: evaluation of adaptation to climate change from a development perspective. Brighton: Institute of Development Studies.

Hiluf, M., et al., 2009. Ethiopia - the impact of client oriented services: the Rural Capacity Building Project (RCBP). Ministry of Agriculture and Rural Development. Presented at the Cross-Country Workshop for Impact Evaluations in Agriculture and Community Driven Development, Addis Ababa, 13-16 April. 
Huang, Y. and Barker, T., 2009. The clean development mechanism and sustainable development: a panel data analysis. Working paper 130. Cambridge: Tyndall Centre for Climate Change Research.

Huq, S. and Reid, H., 2004. Mainstreaming adaptation in development. IDS bulletin, 35 (3), 15-21.

Huq, S. and H. Reid., 2007. Community-based adaptation: a vital approach to the threat climate change poses to the poor. IIED briefing paper. London: International Institute for Environment and Development.

Ibarrarán, M.I., et al., 2009. Climate change and natural disasters: macroeconomic performance and distributional impacts. Environment, development and sustainability, 11, 549-569.

IETA, n.d. What are carbon sinks. Available from: http://www.ieta.org/ieta/www/pages/ index.php?IdSitePage=124 [Accessed 11 August 2009].

Independent Evaluation Group, 2008a. The welfare impact of rural electrification: a reassessment of the costs and benefits - an IEG impact evaluation. Washington, DC: World Bank Group.

Independent Evaluation Group, 2008b. An impact evaluation of India's second and third Andra Pradesh irrigation projects - a case of poverty reduction with low economic returns. Washington, DC: World Bank Group.

International Institute for Sustainable Development, 2003. Sustainable drylands management: a strategy for securing water resources and adapting to climate change. Information paper 3, Livelihoods and climate change - combining disaster risk reduction and natural resource management. December. Winnipeg, Canada: IISD.

IPCC, 2001. Climate change 2001: Working Group II: impacts, adaptation and vulnerability. Available from: http://www.grida.no/climate/ipcc_tar/wg2/index.htm [Accessed 22 June 2009].

IPCC, 2007a. Summary for policymakers. In: S. Solomon et al., eds. Climate change 2007: the physical science basis. contribution of Working Group I to the fourth assessment report of the Intergovernmental Panel on Climate Change. Cambridge: Cambridge University Press, 1-17.

IPCC, 2007b. Summary for policymakers. In: M.L. Parry et al., eds. Climate change 2007: impacts, adaptation and vulnerability. Contribution of Working Group II to the fourth assessment report of the Intergovernmental Panel on Climate Change. Cambridge: Cambridge University Press, 7-22.

ISDR, 2009. Global assessment report on disaster risk reduction. Geneva: United Nations.

Jones, N.C., et al., 2008. Improving impact evaluation coordination and uptake. Scoping study commissioned by the DFID Evaluation Department. January. London: Overseas Development Institute.

Kahn, M., 2005. The death toll from natural disasters: the role of income, geography and institutions. Review of economics and statistics, 87 (2), 271-284.

Kallbekken, S., 2006. Why the CDM will reduce carbon leakage. Climate policy, 7, 197-211.

Karsenty, A., 2008. REDD and the evolution of an international forest regime. The architecture of proposed REDD schemes after Bali. International forestry review, 10 (3), 443-457.

Kassie, M., et al., 2009. Sustainable agricultural practices and agricultural productivity in Ethiopiadoes agroecology matter? Environment for development discussion paper series EfD DP 09-12. April. Washington, DC: Environment for Development Initiative and Resources for the Future.

Keane, J. and G. Potts, 2008. Achieving 'green growth' in a carbon constrained world. ODI background note. October. London: ODI.

Kranjac-Berisavljevic, G., et al., 2009. Climate change. In: B.D. McIntyre et al., eds. Agriculture at a crossroads - international assessment of agricultural knowledge, science and technology for development: synthesis report. Washington, DC: Island Press, 46-52.

Kundzewicz, Z.W., et al., 2007. Freshwater resources and their management. In: M.L. Parry et al., eds. Climate change 2007: impacts, adaptation and vulnerability. Contribution of Working Group II to the fourth assessment report of the Intergovernmental Panel on Climate Change. Cambridge: Cambridge University Press, 173-210.

Leeuw, F. and Vaessen, J., 2009. Impact evaluations and development - NONIE guidance on impact evaluation. Washington, DC: The Network of Networks on Impact Evaluation, c/o the Independent Evaluation Group, World Bank.

Liverman, D., 2007. From uncertain to unequivocal - the IPCC fourth assessment report on the physical science basis of climate change. Environment, 49 (8), 36-39.

Liverman, D., 2008. Assessing impacts, adaptation and vulnerability: reflections on the Working Group II report of the Intergovernmental Panel on Climate Change. Global environmental change, 18, 4-7.

Luttrell, C., Schreckenberg, K. and Peskett, P., 2007. The implications of carbon financing for propoor community forestry. ODI forestry briefing 14 . London: ODI. 
MacGregor, J. and Vorley, B., 2006. Fair miles? Weighing environmental and social impacts of fresh produce exports from sub-Saharan Africa to the UK (summary). Fresh insights no. 9. London: IIED.

McGray, H., et al., 2007. Weathering the storm - options for framing adaptation and development. Washington, DC: World Resources Institute.

McMullen, C.P. and Jabbour, J., 2009. Climate change science compendium 2009. United Nations Environment Programme. Nairobi: EarthPrint.

Mendelsohn, R. and Dinar, A., 1999. Climate change, agriculture, and developing countries: does adaptation matter? World Bank research observer, 14 (2), 277-293.

Michaelowa, A. and Purohit, P., 2007. Additionality determination of Indian CDM projects. Can Indian CDM project developers outwit the CDM Executive Board? Zurich: University of Zurich.

Mitchell, D., 2008. A note on rising food prices. Policy research working paper 4682. Washington, DC: World Bank.

Mitchell, J., Ashley, C. and Mann, S., 2007. Can tourism offer pro-poor pathways to prosperity? ODI briefing paper. London: ODI.

Mitchell, T. and Tanner, T., 2007. Embedding climate change adaptation in development processes. IDS in focus, no. 2. Brighton: Institute of Development Studies.

Mortimore, M.J. and Adams, W.M., 2001. Farmer adaptation, change and 'crisis' in the Sahel. Global environmental change, 11 (1), 49-57.

Muller, A., 2009. Benefits of organic agriculture as a climate change adaptation and mitigation strategy for developing countries. Environment for development discussion paper series EfD DP 09-09. April. Washington, DC: Environment for Development Initiative and Resources for the Future.

Musopole, R., et al., 2009. Malawi - evaluation of the agricultural development program support. Presented at the Cross-Country Workshop for Impact Evaluations in Agriculture and Community Driven Development, Addis Ababa, 13-16 April.

Neeff, T. and Ascui, F., 2009. Lessons from carbon markets for designing an effective REDD architecture. Climate policy, 9 (3), 306-315.

O'Brien, K., et al., 2008. Disaster risk reduction, climate change adaptation and human security. A commissioned report for the Norwegian Ministry of Foreign Affairs by the Global Environmental Change and Human Security (GECHS) Project, GECHS Report 2008:3.

OECD, 2006. Putting climate change adaptation in the development mainstream. Policy brief. March. Paris: OECD.

OECD, 2009a. Integrating climate change adaptation into development co-operation: policy guidance. Paris: OECD.

OECD, 2009b. Development perspectives for a post-Copenhagen climate financing architecture. Paris: OECD.

Ogle, S.M., et al., 2007. An empirically based approach for estimating uncertainty associated with modelling carbon sequestration in soils. Ecological modelling, 205, 453-463.

Olsen, K.H., 2007. The clean development mechanism's contribution to sustainable development: a review of the literature. Climatic change, 84 (1), 59-73.

Ostrom, E., 2007. A diagnostic approach for going beyond panaceas. Proceedings of the National Academy of Sciences, 104 (39), 15181-15187.

Oswald, K., 2009. The role of social protection in adapting to climate change. Climate lite, February. Brighton: Climate Change and Development Centre, Institute for Development Studies.

Paavola, J. and Adger, N.W., 2006. Fair adaptation to climate change. Ecological economics, 56 (4), 594-609.

Parry, M.L., et al., eds, 2007. Climate change 2007: impacts, adaptation and vulnerability. Contribution of Working Group II to the fourth assessment report of the Intergovernmental Panel on Climate Change. Cambridge: Cambridge University Press.

Paulsson, E., 2009. A review of the CDM literature: from fine-tuning to critical scrutiny? International environmental agreements, 9, 63-80.

Peskett, L. and Harkin, Z., 2007. Risk and responsibility in reduced emission from deforestation and degradation. ODI forestry briefing 15 . London: ODI.

Peskett, L., Luttrell, C. and Iwata, M., 2007. Can standards for voluntary carbon offsets ensure development benefits? ODI forestry briefing 13 . London: ODI.

Petrokovsky, G., et al., 2009. Draft protocol for the systematic review: comparison of methods for the measurement and assessment of carbon stocks and carbon stock changes in terrestrial carbon pools. Draft. Available from: http://www.environmentalevidence.org/Documents/Draftprotocol 77.pdf [Accessed 26 October 2009]. 
Pfaff, A., Robalino, J. and Sánches-Azofeifa, G.A., 2008. Payments for environmental services: empirical analysis for Costa Rica. Working paper series SAN-0805. Durham, NC: Duke University, Terry Sandford School of Public Policy.

Phelps, J., et al., 2010. What makes a 'REDD' country? Global environmental change, 20 (2), 322-332.

Pielke, R., et al., 2007. Lifting the taboo on adaptation. Nature, 445, 597-598.

Piesse, J. and Thirtle, C., 2009. Three bubbles and a panic: an explanatory review of recent food commodity price events. Food policy, 34 (2), 119-129.

Porrúra, M.E., Corbera, E. and Brown, K., 2007. Reducing greenhouse gas emissions from deforestation in developing countries: revisiting the assumptions. Working paper 115. Norwich: Tyndall Centre for Climate Change Research.

Prowse, M., 2007a. Making contract farming work with co-operatives. ODI opinion 87. October. London: ODI.

Prowse, M., 2007b. Aid effectiveness: the role of qualitative research in impact evaluation. ODI background note. London: ODI.

Prowse, M. and Camfield, L., 2009. What role for qualitative methods in randomized experiments? IOB working paper 2009.05. Antwerp: Institute of Development Policy and Management, University of Antwerp, IOB.

PT. Pelangi Energi Abadi Citra Enviro, 2007. Working paper: Indonesia and Climate change current status and policies. Available from: https://www.uktradeinvest.gov.uk/ukti/fileDownload/ climatechange.pdf?cid=411082 [Accessed 22 June 2009].

Rajagopal, D. and Zilberman, D., 2007. Review of environmental, economic and policy aspects of biofuels. Policy research working paper 4341. Washington, DC: World Bank.

Ramalingam, B. and Jones, H., 2008. Strategic futures planning: a guide for public sector organisations. London: Overseas Development Institute.

Ravallion, M., 2001. The mystery of the vanishing benefits: an introduction to impact evaluation. World Bank economic review, 15 (1), 115-140.

Ravallion, M., 2005. Evaluating anti-poverty programs. Policy research working paper 3625. Washington, DC: The World Bank.

Reid, H. and Swiderska, K., 2008. Biodiversity, climate change and poverty: exploring the links. IIED briefing. February. London: International Institute for Environment and Development.

Robalino, J., et al., 2008. Deforestation impacts of environmental services payments: Costa Rica's PSA Program 2000-2005. Environment for development discussion paper series EfD DP 08-24. Washington, DC: Environment for Development Initiative and Resouces for the Future.

Rogers, P.J., 2007. Theory-based evaluation: reflections ten years on. New directions for evaluation, $114,63-81$.

Rosegrant, M. and Hazell, P., 2000. Transforming the rural Asian economy: the unfinished revolution. Hong Kong: Oxford University Press.

Rosenzweig, C., et al., 2007. Assessment of observed changes and responses in natural and managed systems. In: M.L. Parry et al., eds. Climate change 2007: impacts, adaptation and vulnerability. Contribution of Working Group II to the fourth assessment report of the Intergovernmental Panel on Climate Change. Cambridge: Cambridge University Press, 79-131.

Sabates-Wheeler, R., Mitchell, T. and Ellis, F., 2008. Avoiding repetition: time for CBA to engage with the livelihoods literature? IDS bulletin, 39 (4), 53-59.

Schneider, L., 2007. Is the CDM fulfilling its environmental and sustainable development objectives? An evaluation of the CDM and options for improvement. Report prepared for WWF. Berlin: Institute for Applied Ecology.

Schultz, T.P., 2004. School subsidies for the poor: evaluating the Mexican Progresa Poverty Program. Journal of development economics, 74 (1), 199-250.

Searchinger, et al., 2008. Use of U.S. croplands for biofuels increases greenhouse gases through emissions from land-use change. Science, 319, 1238.

Sims, K.R.E., 2008. Environment v. development: evidence from Thai protected areas. Working paper, Amherst College. Available from: https://www.amherst.edu/media/view/115011/original/Sims Thai PA_9-28-08.pdf [Accessed 9 June 2009].

Sims, R., et al., 2008. From 1st- to 2nd-generation biofuel technologies: an overview of current industry and RD\&D activities. Paris: Organisation for Economic Cooperation and Development/ International Energy Agency. Available from: http://www.iea.org/publications/free_new_Desc. asp?PUBS_ID=2079 [Accessed 15 June 2009]. 
Skoufias, E., 2001. PROGRESA and its impacts on the human capital and welfare of households in rural Mexico: a synthesis of the results of an evaluation by IFPRI. Washington, DC: International Food Policy Research Institute.

Smit, B. and Wandel, J., 2006. Adaptation, adaptive capacity and vulnerability. Global environmental change, 16, 282-292.

Smith, J.L., 2009. World oil: market or mayhem? The journal of economic perspectives, 23 (3), 145-164.

Smith, P., et al., 2007. Agriculture. In: B. Metz et al., eds. Climate change 2007: mitigation. Contribution of Working Group III to the fourth assessment report of the Intergovernmental Panel on Climate Change. Cambridge: Cambridge University Press, 497-540.

Somanathan, E., Prabhakar, R. and Mehta, B.S., 2009. Decentralization for cost-effective conservation. Proceedings of the National Academy of Sciences of the United States of America, 106 (11), 4143-4147.

Sue Wing, I. and Kolodziej, M., 2009. The regional greenhouse gas initiative: emission leakage and the effectiveness of interstate border adjustments. Available from: http://papers.ssrn.com/sol3/ papers.cfm?abstract_id=1448748 [Accessed 26 October 2009].

Sutter, C. and Parreño, J.C., 2007. Does the current clean development mechanism (CDM) deliver its sustainable development claim? An analysis of officially registered CDM projects. Climatic change, 84 (1), 75-90.

Tessema, I., et al., 2009. Ethiopia Nile irrigation and drainage project impact evaluation. Presented at the Cross-Country Workshop for Impact Evaluations in Agriculture and Community Driven Development, Addis Ababa, 13-16 April.

Thomalla, F., et al., 2006. Reducing hazard vulnerability: towards a common approach between disaster risk reduction and climate change. Disasters, 30 (1), 39-48.

Thomas, D.S.G. and Twyman, C., 2005. Equity and justice in climate change adaptation amongst natural-resource-dependent societies. Global environmental change Part A, 15 (2), 115-124.

Todd, D. and Brann, J., 2007. GEF impact evaluation: approach paper. Impact evaluation information document no. 1. Washington, DC: GEF Evaluation Office.

Uchida, E., et al., 2007. Are the poor benefiting from China's land conservation program? Environment and development economics, 12, 593-620.

UNDP, 2004. A global report-reducing disaster risk: a challenge for development. New York: United Nations Development Programme.

UNDP, 2007. Human Development Report 2007/2008: fighting climate change: human solidarity in a divided world. Basingstoke: Palgrave Macmillan.

UNFCCC, 2006. Report of the Conference of the Parties serving as the meeting of the Parties to the Kyoto Protocol on its first session, Montreal, 28 November-10 December 2005. Addendum Part Two. FCCC/KP/CMP/2005/8/Add.1, 30 March.

UNFCCC, 2007. Investment and financial flows to address climate change. Bonn: United Nations Convention on Climate Change Secretariat.

UNFCCC, 2008. Investment and financial flows to address climate change: an update. Technical paper FCCC/TP/2008/7. Bonn: UNFCCC.

UNFCCC, 2009. Report on opportunities and challenges for mitigation in the agricultural sector summary by the chair of the workshop. Ad hoc working group on long-term cooperative action under the convention, fifth session, Bonn, 29-8 April. FCCC/AWGLCA/2009/CRP.2

United Nations, 1992. United Nations Framework Convention on Climate Change. Available from: http:// unfccc.int/essential_background/convention/background/items/2853.php [Accessed 12 June 2009].

United Nations, 1998. Kyoto Protocol to the United Nations Framework Convention on Climate Change. Available from: http://unfccc.int/resource/docs/convkp/kpeng.pdf [Accessed 16 December 2009].

Vakis, R., 2006. Complementing natural disasters management: the role of social protection. Social protection discussion paper 0543. Washington, DC: World Bank.

Wara, M.W and Victor, D.G., 2008. A realistic policy on international carbon offsets. Program on energy and sustainable development working paper 74. Stanford: Stanford University, Freeman Spogli Institute for International Studies.

Warren, R., et al., 2006. Understanding the regional impacts of climate change. Report prepared for the Stern Review. Tyndall Centre working paper 90. Norwich: Tyndall Centre.

Weiss, C.H., 2007. Theory-based evaluation: past, present, and future. In: P.J. Rogers, ed. Theorybased evaluation: reflections ten years on. New directions for evaluation, 114, 63-81.

White, H., 2006. Impact evaluation: the experience of the independent evaluation group of the World Bank. Washington, DC: World Bank. 
White, H., 2009a. Some reflections on current debates in impact evaluation. Working paper 1. April. New Delhi: International Initiative for Impact Evaluation.

White, H., 2009b. Theory-based impact evaluation: principles and practice. Journal of development effectiveness, 1 (3), 271-284.

White, H., 2009c. Using impact evaluation to increase the efficacy of climate change interventions. In: R.D. Van Den Berg and O.N. Feinstein, eds. Evaluating climate change and development. World Bank series on development volume 8. New Brunswick: Transaction, 105-113.

Wiggins, S. and Levy, S., 2008. Rising food prices: cause for concern? ODI briefing paper. London: Overseas Development Institute.

Woolcock, M., 2009. Towards a plurality of methods in project evaluation: a contextualised approach to understanding impact trajectories and efficacy. Journal of development effectiveness, 1 (1), 1-14.

World Bank, 2007. World Development Report 2008: agriculture for development. Washington, DC: World Bank

World Bank, 2008. Global Monitoring Report 2008 - MDGs and the environment: agenda for inclusive and sustainable development. Washington, DC: World Bank.

World Bank, 2009a. Convenient solutions to an inconvenient truth: ecosystem-based approaches to climate change. Washington, DC: World Bank.

World Bank, 2009b. World Development Report 2010: development in a changing climate. Washington, DC: World Bank.

World Bank, 2009c. Countries join initiative to improve their prospects for agricultural development. Available from: http://web.worldbank.org/WBSITE/EXTERNAL/NEWS/0,,print:Y isCURL: $\mathrm{Y} \sim$ contentMDK:22257563 pagePK:64257043 piPK:437376 theSitePK:4607,00.html [Accessed 25 November 2009].

World Meteorological Organisation, 2009. WMO Greenhouse gas bulletin - the state of greenhouse gases in the atmosphere using global observations through 2008. WMO greenhouse gas bulletin no. 5, 23 November. Geneva: WMO.

World Resources Institute, 2009. Climate analysis indicators tool. Version 7.0. Available from: http:// cait.wri.org/cait.php [Accessed 7 January 2010].

Yamin, F., Rahman, A. and Huq, S., 2005. Vulnerability, adaptation and climate disasters: a conceptual overview. IDS bulletin, 36 (4), 1-14. 